\title{
A Sophisticated Network of Signaling Pathways Regulates Stomatal Defenses to Bacterial Pathogens
}

\author{
Dominique Arnaud ${ }^{*}$ and lldoo Hwang \\ Department of Life Sciences, POSTECH Biotech Center, Pohang University of Science and Technology, Pohang 790-784, Korea \\ *Correspondence: Dominique Arnaud (arnaud@postech.ac.kr) \\ http://dx.doi.org/10.1016/j.molp.2014.10.012
}

\section{ABSTRACT}

Guard cells are specialized cells forming stomatal pores at the leaf surface for gas exchanges between the plant and the atmosphere. Stomata have been shown to play an important role in plant defense as a part of the innate immune response. Plants actively close their stomata upon contact with microbes, thereby preventing pathogen entry into the leaves and the subsequent colonization of host tissues. In this review, we present current knowledge of molecular mechanisms and signaling pathways implicated in stomatal defenses, with particular emphasis on plant-bacteria interactions. Stomatal defense responses begin from the perception of pathogen-associated molecular patterns (PAMPs) and activate a signaling cascade involving the production of secondary messengers such as reactive oxygen species, nitric oxide, and calcium for the regulation of plasma membrane ion channels. The analyses on downstream molecular mechanisms implicated in PAMP-triggered stomatal closure have revealed extensive interplays among the components regulating hormonal signaling pathways. We also discuss the strategies deployed by pathogenic bacteria to counteract stomatal immunity through the example of the phytotoxin coronatine.

Key words: stomata, immunity, hydrogen peroxide, nitric oxide, calcium, hormones

Arnaud D. and Hwang I. (2015). A Sophisticated Network of Signaling Pathways Regulates Stomatal Defenses to Bacterial Pathogens. Mol. Plant. 8, 566-581.

\section{INTRODUCTION}

\section{The Plant Immune System}

Plants are continuously exposed to diverse phytopathogenic microorganisms and have elaborated a variety of defense mechanisms to successfully avoid infection by limiting pathogen invasion and multiplication. The first layer of the plant innate immunity is initiated by the recognition of evolutionary conserved elicitors called pathogen-associated molecular patterns (PAMPs) by surface-localized pattern recognition receptors (PRRs) (Jones and Dangl, 2006; Monaghan and Zipfel, 2012). The Arabidopsis PPR leucine-rich repeat receptor-like kinase (LRRRLK) FLAGELLIN-SENSING2 (FLS2) binds to the bacterial PAMP flagellin. Another well-characterized PPR is the EF-Tu RECEPTOR (EFR) that recognize the bacterial elongation factor Tu (EF-Tu). The PAMP chitin, a component of the fungal cell wall, also induces defense responses and is recognized by the LysM-RLK CHITIN ELICITOR RECEPTOR KINASE1 (CERK1) in Arabidopsis. Host-derived damage-associated molecular pattern (DAMP) such as plant peptides (Peps) and cell wall fragments are released upon pathogen infection or wounding and, like PAMPs, are able to trigger immune responses. The Arabidopsis LRR-RLKs PEPR1 and PEPR2 are the PPRs for Peps, and the EGF-like RLK CELL WALL-ASSOCIATED KINASE1 (WAK1) recognizes oligogalacturonides (OGs), a degradation product of the plant cell wall (Monaghan and Zipfel, 2012).

PAMPs perception initiates a variety of basal defense responses effective in stopping the invasion by most potential pathogens, referred to as PAMP-triggered immunity (PTI), which mostly includes the activation of mitogen-activated protein kinases (MAPK), alkalinization of the extracellular space, reactive oxygen species (ROS) and nitric oxide (NO) production, increase in $\mathrm{Ca}^{2+}$ influx, activation of the salicylic acid (SA) pathway, synthesis of ethylene, and stomatal closure (Boller and Felix, 2009). In return, adapted and successful pathogens secrete a number of effector proteins through the type III secretion system (T3S) or toxins to evade or actively suppress PTI (Jones and Dangl, 2006; Dou and Zhou, 2012). A second layer of immunity is mediated by resistance $(R)$ genes that directly or indirectly recognize pathogen effectors secreted within the host cells. This recognition activates robust defense responses such as

Published by the Molecular Plant Shanghai Editorial Office in association with Cell Press, an imprint of Elsevier Inc., on behalf of CSPB and IPPE, SIBS, CAS. 
localized cell death or hypersensitive response that inhibits pathogen invasion. This $\mathrm{R}$ protein-mediated defense is also called effector-triggered immunity or ETI (Jones and Dangl, 2006).

\section{Stomata Function in Plant Development and Abiotic Stress}

Stomata are microscopic pores surrounded by a pair of guard cells, located at the leaf epidermis. They control gas exchanges between the leaves and the atmosphere, notably $\mathrm{CO}_{2}$ uptake for photosynthesis and water loss during transpiration. Each pair of guard cells regulates the aperture of its circumscribed stomatal pore by turgor-driven volume changes. The regulation of stomatal opening and closing is under the control of environmental and internal signals such as light, drought, $\mathrm{CO}_{2}$ concentration, relative humidity, microbes, and plant hormones (Melotto et al., 2008; Acharya and Assmann, 2009; Sirichandra et al., 2009b).

During light-induced stomatal opening, plasma membrane anion channel activity is reduced and the plasma membrane $\mathrm{H}^{+}$ATPase activity is increased, leading to $\mathrm{H}^{+}$extrusion and acidification of the extracellular medium. The increase in $\mathrm{H}^{+}$-ATPase activity also results in a hyperpolarization of the membrane potential that provides the driving force for the activation of inward-rectifying $\mathrm{K}^{+}\left(\mathrm{K}^{+}{ }_{\text {in }}\right)$ channels mediating $\mathrm{K}^{+}$influx. $\mathrm{K}^{+}$accumulation, which is accompanied by an influx of anions, results in water uptake, an increase in guard cell turgor, and stomatal opening (Sirichandra et al., 2009b). Stomatal closure in response to abiotic stress, in which the phytohormone abscisic acid (ABA) is a key regulator, is initiated when the guard cell membrane depolarizes as a result of inhibition of $\mathrm{H}^{+}$extrusion combined with opening of slow (S)- and rapid (R)-type anion channels that mediate the efflux of $\mathrm{Cl}^{-}$, malate, and $\mathrm{NO}^{3-}$ anions. Membrane depolarization activates voltage-regulated outward-rectifying $\mathrm{K}^{+}\left(\mathrm{K}^{+}\right.$out $)$channels, resulting in $\mathrm{K}^{+}$efflux. The consequent massive loss of solutes drives water efflux from the guard cells and decreases guard cell turgor, narrowing the stomatal pore (Sirichandra et al., 2009b).

It is well documented that ROS and calcium function as second messengers in ABA signal transduction cascade in guard cells (Wang and Song, 2008; Kim et al., 2010). ABA-induced ROS accumulation in guard cells is mainly generated by the NADPH oxidases respiratory burst oxidase homolog (RBOH), and mutations in both $R B O H D$ and $R B O H F$ genes impaired $A B A$-induced stomatal closing (Pei et al., 2000; Kwak et al., 2003). It is also well known that $A B A$-induced stomatal closure involves two parallel $\mathrm{Ca}^{2+}$-dependent and $\mathrm{Ca}^{2+}$-independent signaling pathways for the activation of anion channels (Kim et al., 2010). ABA-stimulated ROS accumulation in guard cells activates nonselective $\mathrm{Ca}^{2+}$-permeable cation $\left(\mathrm{l}_{\mathrm{Ca}}\right)$ channels mediating $\mathrm{Ca}^{2+}$ influx from apoplast and induces cytosolic calcium $\left[\mathrm{Ca}^{2+}\right]_{\text {cyt }}$ oscillations. ABA-induced $\left[\mathrm{Ca}^{2+}\right]_{\text {cyt }}$ elevations activate the S-type anion channels and suppress the $\mathrm{K}^{+}$in channels, leading to stomatal closure (Kim et al., 2010).

$\mathrm{NO}$ is an important regulator of ABA-induced stomatal closure (Desikan et al., 2002; Guo et al., 2003). ABA-mediated NO production involves NITRATE REDUCTASE (NR) and NO
SYNTHASE1 (NOS1) in guard cells. It has been found that NOS1 is a cGTPase but not an NO synthase and has been renamed NITRIC OXIDE ASSOCIATED PROTEIN1 (NOA1) (Moreau et al., 2008). NO production occurs downstream of ROS production in guard cell ABA signaling (Bright et al., 2006), and $\mathrm{NO}$ activates anion channels, $\mathrm{K}^{+}$out channels, and both endomembrane and plasma membrane $\mathrm{Ca}^{2+}$ channels and inactivates $\mathrm{K}^{+}{ }_{\text {in }}$ channels (García-Mata et al., 2003; GarcíaMata and Lamattina, 2013).

\section{STOMATAL IMMUNITY RESTRICTS PATHOGEN ENTRY INTO THE LEAVES}

A wide range of foliar pathogens including bacteria, fungi, oomycetes, and virus are known to disrupt stomatal movements during infection, and these aspects have been recently reviewed (Grimmer et al., 2012; McLachlan et al., 2014). Studies have shown that stomata are not just a passive port for pathogen entry but play an active role in the plant innate immune response, and the control of stomatal closure is one of the first lines of defense against pathogen invasion (Melotto et al., 2006). Plants can restrict pathogen entry into the leaves by closing stomata or by inhibiting stomatal opening. Conversely, pathogens have evolved virulence factors to counteract host stomatal defenses by inhibiting stomatal closure or promoting stomatal opening. The aim of this review is to discuss the current knowledge on stomatal responses to PAMPs and bacteria.

\section{Stomatal Closure and Reopening in Response to Bacterial Pathogens}

Most plant pathogenic bacteria must first enter plant tissues to initiate pathogenesis, and rely on wounds or natural openings such as hydathodes and stomata to penetrate the apoplastic space. For example, Xanthomonas campestris pv. campestris $(X c c)$ enters leaves preferentially through stomata or hydathodes depending on the Arabidopsis ecotype, while $X$. campestris pv. armoraciae bacteria use mostly stomata to colonize Arabidopsis leaves (Hugouvieux et al., 1998; Gudesblat et al., 2009). The virulent Pseudomonas syringae pv. tomato (Pst) strain DC3000 selectively moves toward open stomata to enter into the leaves (Melotto et al., 2006). Most of studies on stomatal immunity using bacteria have been performed on the widely used model pathosystem Pst DC3000/Arabidopsis (Xin and He, 2013).

Pioneer works have shown that virulent Pst DC3000 induces stomatal closure and a decrease in stomatal conductance within 1 to $2 \mathrm{~h}$ post-inoculation (hpi) in Arabidopsis. However, Pst DC3000mediated stomatal closure is transient because stomata reopen between 2.5 and 5 hpi (Melotto et al., 2006; Freeman and Beattie, 2009). Pst DC3000-mediated stomatal closure and subsequent reopening was also observed in another host plant, tomato (Solanum lycopersicum; Melotto et al., 2006; Du et al., 2014). Stomata reopening was attributed to the virulence factor coronatine (COR), a polyketide toxin secreted by certain Pseudomonas strains such as Pst DC3000 and $P$. syringae pv. maculicola ES4326 (Psm ES4326). Indeed, the COR-deficient bacteria strain Pst DC3118 is unable to reopen stomata after 3 hpi (Melotto et al., 2006). Moreover, compared with wild-type (WT) Pst bacteria, the growth of COR-deficient Pst bacteria in 
Molecular Plant

planta was shown to be much reduced (over 100-fold) after surface inoculation than after direct infiltration into the apoplast (Mittal and Davis, 1995; Brooks et al., 2004; Melotto et al., 2006; Zeng and He, 2010). Therefore, COR-deficient bacteria strains have been used as a tool for the functional characterization of genes involved in bacterium-induced stomatal closure (Melotto et al., 2006; Zeng and He, 2010; Desclos-Theveniau et al., 2012; Du et al., 2014; Kadota et al., 2014), as well as for a genetic screening of susceptible to coronatine-deficient Pst DC3000 (scord) mutants (Zeng et al., 2011).

Other pathogenic bacterial strains which do not produce COR are also able to induce stomatal closure and subsequent reopening, as exemplified for $P$. syringae pv. tabaci $(P t a)$ on its host tobacco (Nicotiana tabacum) and for Xcc on Arabidopsis (Melotto et al., 2006; Gudesblat et al., 2009). An unknown diffusible virulence factor secreted in the extracellular medium is responsible for Xcc-mediated stomatal reopening (Gudesblat et al., 2009). Bacteria-induced stomatal closure is not exclusive to (hemi-) biotrophic pathogens, as the necrotrophic bacteria Pectobacterium carotovorum ssp. carotovorum ( $P c c)$ were also shown to cause stomatal closure during infection (Arnaud et al., 2012; Singh et al., 2012). Non-host bacteria such as the human pathogen Escherichia coli strain 0157:H7 and the non-pathogenic strain Pseudomonas fluorescens A506 were shown to induce a sustained stomatal closure from 1 to 8 hpi (Melotto et al., 2006; Freeman and Beattie, 2009). Salmonella enterica bacteria, another human pathogen, move toward stomata of lettuce (Lactuca sativa) by chemotaxis to penetrate inner leaf tissues in the light but not in the dark, suggesting that the pathogen is attracted by nutrients produced during photosynthesis (Kroupitski et al., 2009). Depending on experimental setups, Salmonella induce either a slight stomatal closure compared with Pst DC3000 on lettuce (Kroupitski et al., 2009), or a significant but transient stomatal closure at $2 \mathrm{hpi}$, with a reopening at $4 \mathrm{hpi}$, on both lettuce and Arabidopsis (Roy et al., 2013). Whether Salmonella avoid recognition by plants or can suppress plant defense responses and induce disease symptoms has been a matter of debate (Schikora et al., 2012; Melotto et al., 2014).

These studies indicate that stomatal defenses are effective against a wide range of bacteria with different lifestyles. During the evolution, pathogenic bacteria from different genus have developed virulence factors to counteract stomatal immunity and allow successful penetration into the leaves (Melotto et al., 2006; Gottig et al., 2008; Gudesblat et al., 2009; Kroupitski et al., 2009). On the other hand, the control of stomatal opening by pathogens is also certainly important for facilitating pathogen release and reinfection to other plants (Grimmer et al., 2012).

\section{Recognition of Pathogens at the Leaf Surface, PAMPs Perception by PPRs}

In Arabidopsis, the promotion of stomatal closure by pathogenic and non-pathogenic living bacteria is mediated by the perception of PAMPs such as lipopolysaccharide (LPS), and the peptides elf26 and flg22, the biologically active epitopes of flagellin and EF-tu, respectively (Figure 1A; Melotto et al., 2006, Desikan et al., 2008). The peptide flg22 induces a stomatal closure with a concomitant decrease in stomatal conductance and also

\section{Signaling Pathways Regulating Stomatal Immunity}

inhibits light-induced stomatal opening (Melotto et al., 2006; Zhang et al., 2008; Freeman and Beattie, 2009). The flg22 receptor FLS2, expressed in epidermal and guard cells, is required for flg22-induced stomatal responses (Melotto et al., 2006; Zhang et al., 2008; Mersmann et al., 2010). FLS2 plays a prominent role in stomatal closure mediated by WT or CORdeficient Pst bacteria and is required for resistance to sprayinoculated WT, T3S-defective hrcC mutant, or COR-deficient Pst bacteria (Zipfel et al., 2004; Zeng and He, 2010; Li et al., 2014). Importantly, the fls2 mutant is as susceptible as WT plants after infiltration-inoculation with WT or COR-deficient Pst strains, suggesting that FLS2 does not play a major role in post-entry defenses in the apoplast (Zipfel et al., 2004; Zeng and $\mathrm{He}, 2010)$. On the other hand, stomata of fls2 mutant still close in response to LPS treatment and $E$. coli inoculation (Melotto et al., 2006). Because bacteria are supposed to carry multiple PAMPs and fls2 mutant is defective in only one PAMP (flg22), these reports suggest that FLS2 is the main PPR in guard cells that recognize Pst DC3000 during early invasion. Alternatively, Pst DC3000-derived flagellin could be more potent for Pst-induced stomatal closure than other PAMPs, probably because flagellin is necessary for the bacteria to swim through stomatal pores and to invade the apoplastic space.

The PAMP EF-Tu peptide 26 (elf26) derived from $E$. coli is able to close stomata, and EFR is expressed in guard cells (Desikan et al., 2008; Liu et al., 2009). On the other hand, EFR seems not to be required for stomatal closure induced by COR-deficient Pst bacteria and for resistance to spray-inoculated Pst $\mathrm{COR}^{-}$, suggesting that EFR is not essential for stomatal defense against Pst bacteria (Zeng and $\mathrm{He}, 2010$ ). However, it is known that elf26 from Agrobacterium tumefaciens and Erwinia amylovora as well as flg22 are much more effective than elf26 from Pst in inducing PTI (Kunze et al., 2004; Zipfel et al., 2006). It is noteworthy that elf18 from $E$. coli induces stomatal closure, whereas elf18 from Pst does not induce significant stomatal closure (Zeng and $\mathrm{He}$, 2010). Nevertheless, to our knowledge, elf26- or elf18-mediated stomatal closure has not been tested in the efr1 mutant.

Upon elicitation by the peptides flg22 or elf18, FLS2 or EFR rapidly associates with the co-receptor LRR-RK BRI1ASSOCIATED RECEPTOR-LIKE KINASE (BAK1), inducing phosphorylation of both proteins and downstream activation of PTI responses (Monaghan and Zipfel, 2012). In addition to BAK1, the receptor-like cytoplasmic kinase BOTRYTISINDUCED KINASE1 (BIK1) also directly interacts with the PRR complex and is an activator of PTI responses. BIK1 constitutively associates with FLS2, EFR, and BAK1, and is rapidly phosphorylated and released from the PPR complex upon PAMPs perception. BIK1 also associates with CERK1 and PEPR1, indicating that BIK1 is involved in different PPR-mediated signaling pathways (Monaghan and Zipfel, 2012; Liu et al., 2013). Importantly, it was recently demonstrated that BIK1 is required for flg22triggered stomatal closure and for resistance to surfaceinoculated Pst hrcC (Zhang et al., 2010; Li et al., 2014). These results indicate that the FLS2/BIK1 complex is fully required for stomatal immunity whereas, to date, no role for BAK1 in stomatal defense has been reported.

Elicitors like the DAMP oligogalacturonic acid (OGA), a degradation product of the plant cell wall, and the fungal PAMP chitosan, 
A

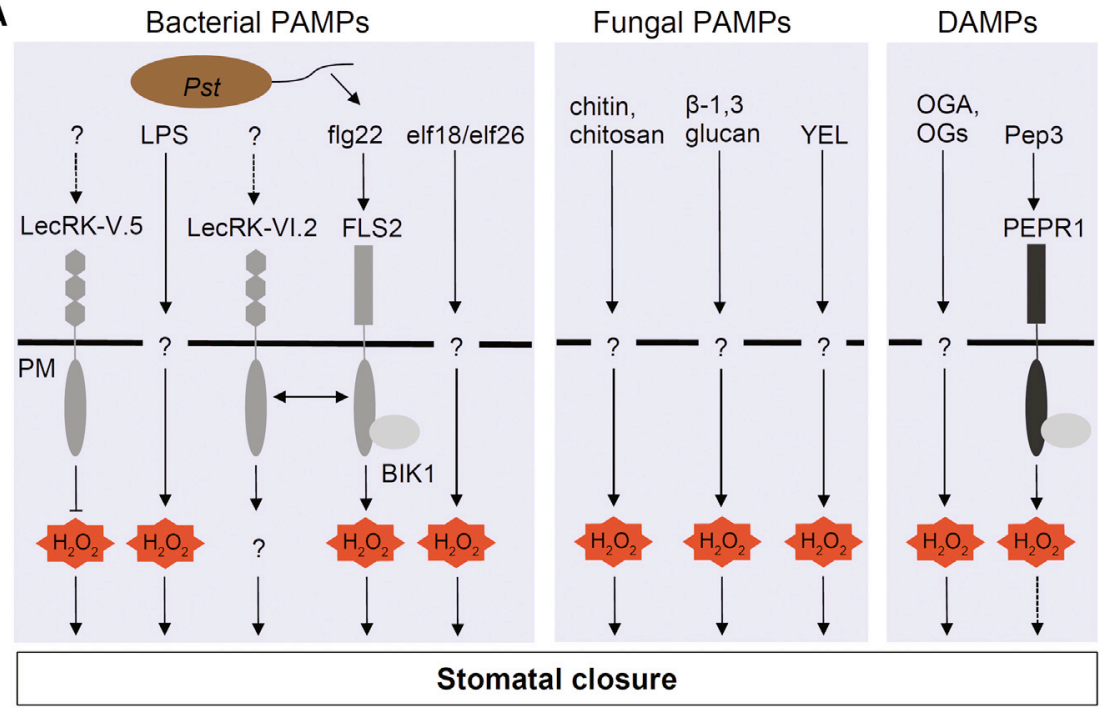

B

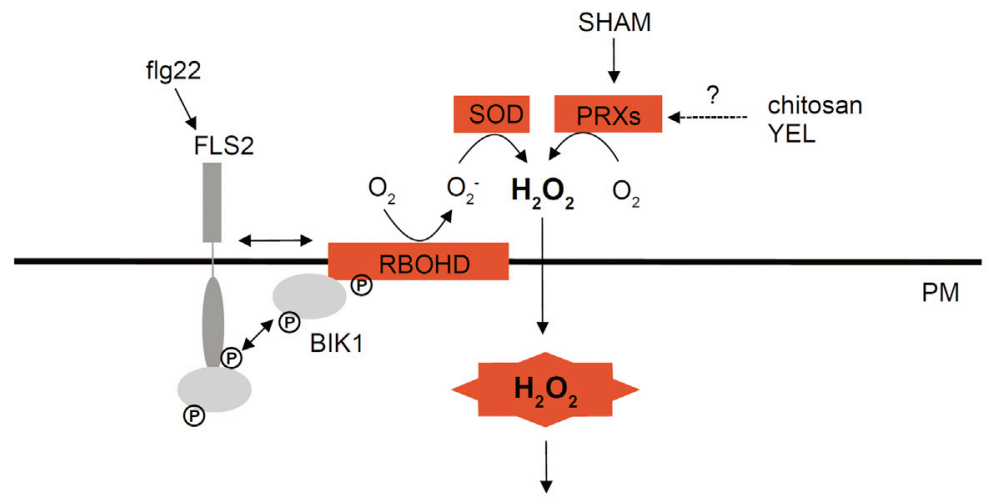

Stomatal closure

Figure 1. PAMP-Mediated ROS Production in Guard Cells and Stomatal Closure.

(A) PAMPs and PPRs known to be implicated in PAMP-induced stomatal closure. The bacterial PAMPs lipopolysaccharide (LPS), flg22, and elf18/ elf26 (the active epitopes of flagellin and elongation factor Tu, respectively) as well as yeast elicitors (YEL) and the fungal PAMPs chitin and $\beta-1,3$ glucans induce ROS production and downstream stomatal closure. The respective PAMPs for LecRK-V.5 and LecRK-VI.2 are unknown but both regulate Pst bacteria-, LPS-, flg22-, and elf26triggered stomatal closure. LecRK-V.5 is a negative regulator of PAMP-mediated ROS production. The LRR-RLK FLS2 mediates flg22- and Pstmediated stomatal closure. The DAMPs oligogalacturonides (OGs) and oligogalacturonic acid (OGA) derived from the plant cell wall promote ROS production and stomatal closure. The endogenous peptide Pep3 induces ROS accumulation through its LRR-RLK receptor PEPR1. There is no evidence that the receptors of elf18/ elf26, chitin, and OGs (EFR, CERK1, and WAK1, respectively) participate in bacteria- or PAMPinduced stomatal closure (see text for details). The PPRs for LPS and $\beta-1,3$ glucans are still unknown. LecRK-VI.2 interacts with FLS2, and the receptor-like cytoplasmic kinase BIK1 implicated in stomatal immunity interacts with FLS2 and PEPR1. Dashed lines and question marks indicate uncertain connections.

(B) PAMP-mediated ROS production in Arabidopsis requires the NADPH oxidase RBOHD and apoplastic peroxidases (PRXs). The recognition of flg22 triggers the phosphorylation of the FLS2 and BAK1 cytoplasmic kinase domains, as well as BIK1. Activated BIK1 is released from the PPR complex and activates RBOHD. RBOHD produces superoxide $\left(\mathrm{O}_{2}^{-}\right)$converted to $\mathrm{H}_{2} \mathrm{O}_{2}$ by superoxide dismutases (SOD). Under the presence of a potent reductant agent, apoplastic peroxidases (PRXs) can directly produce $\mathrm{H}_{2} \mathrm{O}_{2}$ by their
oxidase cycle. $\mathrm{H}_{2} \mathrm{O}_{2}$ can freely diffuse through the plasma membrane to induce stomatal closure. Chitosan and YEL-mediated ROS production is inhibited by SHAM, an inhibitor of PRXs. However, the mechanisms by which chitosan and YEL activate PRXs is unknown.

a deacetylated derivative of chitin, inhibit stomatal opening or induce stomatal closure in tomato, barley, and Arabidopsis (Figure 1A; Lee et al., 1999; Khokon et al., 2010a; Koers et al., 2011). Other oligosaccharidic elicitors such as OGs and $\beta-1,3$ glucans, as well as yeast (Saccharomyces cerevisiae) elicitors (YEL), were also shown to promote stomatal closure or inhibition of stomatal opening in grapevine and Arabidopsis (Klusener et al., 2002; Allègre et al., 2009; Khokon et al., 2010b). Although CERK1 is expressed in guard cells (Liu et al., 2009) there is no evidence that CERK1 mediates chitin- or chitosan-induced stomatal closure. Similarly, it is currently unknown whether the receptor WAK1 is involved in OGs- or OGAtriggered stomatal immunity.

The lectin receptor kinases LecRK-VI.2 and LecRK-V.5 were shown to be positive and negative regulators of stomatal immunity, respectively (Arnaud et al., 2012; Desclos-Theveniau et al., 2012; Singh et al., 2012). LecRK-VI.2 and LecRK-V.5 affect stomatal response to different bacterial PAMPs such as flg22, LPS, and elf26, suggesting that they act downstream of PAMP perception. Interestingly, it was found that LecRK-VI.2 interacts with FLS2 but seems to function independently of BIK1 or BAK1 (Singh et al., 2012; Huang et al., 2014). The identification of the LecRK-VI.2 and LecRK-V.5 extracellular ligands as well as their cytoplasmic interacting partners will shed light on their precise functions in regulating stomatal immunity.

\section{SIGNALING EVENTS DOWNSTREAM OF PAMP PERCEPTION}

\section{ROS Act as Secondary Messengers in Stomatal Defense} Responses

ROS, including superoxide $\left(\mathrm{O}_{2}^{-}\right)$and hydrogen peroxide $\left(\mathrm{H}_{2} \mathrm{O}_{2}\right)$, are widely generated under biotic stresses. Besides their antimicrobial activities and cell wall cross-linking properties for blocking pathogen ingress, ROS are also considered as a local and systemic signaling messenger in plant defense (Torres, 2010). Two major mechanisms have been proposed for the generation of ROS during the oxidative burst upon pathogen attack or elicitation with PAMPs: the apoplastic peroxidases (PRXs) and the plasma membrane NADPH oxidases (Torres, 
Molecular Plant

2010; O'Brien et al., 2012). NADPH oxidases catalyze the production of $\mathrm{O}_{2}{ }^{-}$from oxygen that can be converted to $\mathrm{H}_{2} \mathrm{O}_{2}$ by superoxide dismutase. PRXs can directly generate $\mathrm{H}_{2} \mathrm{O}_{2}$ from $\mathrm{O}_{2}$ under specific conditions (Figure 1B). Besides these enzymes, apoplastic amine oxidases and oxalate oxidase can also mediate ROS production.

ROS have been proposed to function as secondary messengers in the promotion of stomatal closure by diverse hormones (Desikan et al., 2006; Wang and Song, 2008). The bacterial PAMPs flg22, elf26, and LPS induce $\mathrm{H}_{2} \mathrm{O}_{2}$-production in Arabidopsis guard cells (Figure 1A; Desikan et al., 2008; Ma et al., 2009). The DAMP Pep3, a plant peptide, and OGA/OGs as well as other elicitors such as chitosan, $\beta-1,3$ glucan, and YEL promote the production of ROS in guard cells of different plant species, indicating that PAMP-induced stomatal closure requires the synthesis of ROS (Lee et al., 1999; Allègre et al., 2009; Srivastava et al., 2009; Khokon et al., 2010a, 2010b; Ma et al., 2013). These results also suggest that Pep3 can potentially induce stomatal closure. The fls2 and the pepr1 mutants are defective in both flg22- and Pep3-induced ROS production, suggesting an interdependency of PAMP flg22 and DAMP Pep signaling on their respective receptors (Ma et al., 2013).

Many reports have demonstrated the crucial role of the NADPH oxidase RBOHD in PAMP-induced ROS production in leaves by means of oxidative burst assays on leaf disks or on seedlings (Nühse et al., 2007; Zhang et al., 2007; Mersmann et al., 2010). By contrast, RBOHF does not or partially contributes to the flg22-induced oxidative burst depending on the studies (Zhang et al., 2007; Mersmann et al., 2010). However, there is no experimental evidence demonstrating that RBOHD is responsible for PAMP-mediated ROS production specifically in guard cells. Nevertheless, $\mathrm{H}_{2} \mathrm{O}_{2}$ is known to diffuse freely in the apoplastic space and within cells (Allan and Fluhr, 1997) so that $\mathrm{H}_{2} \mathrm{O}_{2}$ produced by epidermal cells might be able to induce stomatal closure in neighboring guard cells.

It has been shown that RBOHD but not RBOHF is required for PAMP- and bacteria-induced stomatal closure (Mersmann et al., 2010; Macho et al., 2012). Infiltration-inoculation experiments indicate that RBOHD is not required for apoplastic defenses against Pst DC3000 (Torres et al., 2002; Zhang et al., 2007; Chaouch et al., 2012). However, the role of RBOHD in disease resistance at the pre-invasive stage is not clear. Conflicting results have been obtained when bacteria are sprayinoculated, and depending on plant growth conditions and Pst strains used, the rbohD mutant displays enhanced or equal susceptibility to Pst bacteria compared with WT plants (Mersmann et al., 2010; Macho et al., 2012; Kadota et al., 2014; Li et al., 2014).

Interestingly, two recent studies have shown that RBOHD is a part of the PPR complex forming ligand-independent associations with BIK1, EFR, and FLS2 (Figure 1B). Moreover, BIK1 directly interacts with and phosphorylates RBOHD upon PAMP perception to regulate its activity (Kadota et al., 2014; Li et al., 2014). RBOHD also directly interacts with FLS2 while BAK1 shows rather a weak interaction with RBOHD in vitro or no interaction in vivo. Importantly, BIK1-mediated RBOHD phosphorylation is important for PAMP- and DAMP-triggered
Signaling Pathways Regulating Stomatal Immunity

oxidative burst in leaves, PAMP-triggered stomatal closure, and resistance to surface-inoculated COR-deficient Pst bacteria (Kadota et al., 2014; Li et al., 2014). Notably, BIK1 might regulate additional signaling components downstream of ROS production during stomatal immunity, as the bik1 mutant is partially defective in $\mathrm{H}_{2} \mathrm{O}_{2}$-mediated stomatal closure ( $\mathrm{Li}$ et al., 2014). Together, these two studies highlighted a direct role of the FLS2/BIK1 complex in the positive regulation of RBOHD activity and stomatal defense.

Chitosan-induced stomatal closure was shown to be inhibited by diphenyleneiodonium chloride (DPI), an inhibitor of NADPH oxidases, in pea (Pisum sativum; Srivastava et al., 2009). However, in Arabidopsis, chitosan- and YEL-induced stomatal closure and ROS production in guard cells are not impaired in the rbohD rbohF double mutant nor by DPI but are inhibited by salicylhydrooxamic acid (SHAM), an inhibitor of apoplastic peroxidases (PRXs; Khokon et al., 2010a, 2010b). Thus, contrary to flg22, chitosan- and YEL-mediated ROS production and stomatal closure appear to be independent of NADPH oxidases and dependent on PRXs in Arabidopsis (Figure 1B). The PRX(s) specifically involved in chitosan- and YEL-induced stomatal closure were not identified, perhaps because they belong to a large family of 73 members (Valério et al., 2004).

\section{Crosstalk between NO Production and Calcium Influx in Stomatal Immunity}

In concert with ROS, nitric oxide (NO) is known to play a role as a signaling molecule in plant defense and in stomatal closure induced by abiotic stress, ABA, and SA (Hao et al., 2010; García-Mata and Lamattina, 2013). Despite a limited number of reports, NO also seems important for stomatal immunity (Figure 2). Treatment of plant with the NO donor sodium nitroprusside (SNP) is known to induce stomatal closure (Desikan et al., 2002). Moreover, flg22 and LPS induce a rapid production of NO in guard cells (Melotto et al., 2006; Ali et al., 2007). Just as for ROS, both flg22- and Pep3-induced NO production in guard cells was reduced in the fls2 and pepr 1 mutants (Ma et al., 2013).

PAMP-induced stomatal closure requires the synthesis of NO (Melotto et al., 2006; Ali et al., 2007). Indeed, treatments with inhibitors of nitric oxide synthase (NOS) prevent LPSdependent NO generation in guard cells as well as PAMP- and bacteria-induced stomatal closure (Melotto et al., 2006; Ali et al., 2007). Importantly, NOA1 (formerly named NOS1) is involved in LPS-dependent NO production in epidermal peels and resistance to spray-inoculated Pst DC3000 (Zeidler et al., 2004). Because ABA- and SA-mediated stomatal closure is dependent on NOS1/NOA1 (Guo et al., 2003; Sun et al., 2010), one can speculate that NOA1 might be also implicated in PAMP-induced stomatal closure.

It has been shown that $\mathrm{NO}$ acts downstream of $\mathrm{H}_{2} \mathrm{O}_{2}$ during chitosan-induced stomatal closure in pea and Arabidopsis (Srivastava et al., 2009; Khokon et al., 2010a). The NO scavenger CPTIO does not impair chitosan-induced ROS production in Arabidopsis guard cells, and chitosan- and YEL-induced NO production occurs downstream of ROS generated by SHAM-sensitive PRXs (Khokon et al., 2010a, 2010b). One of the 


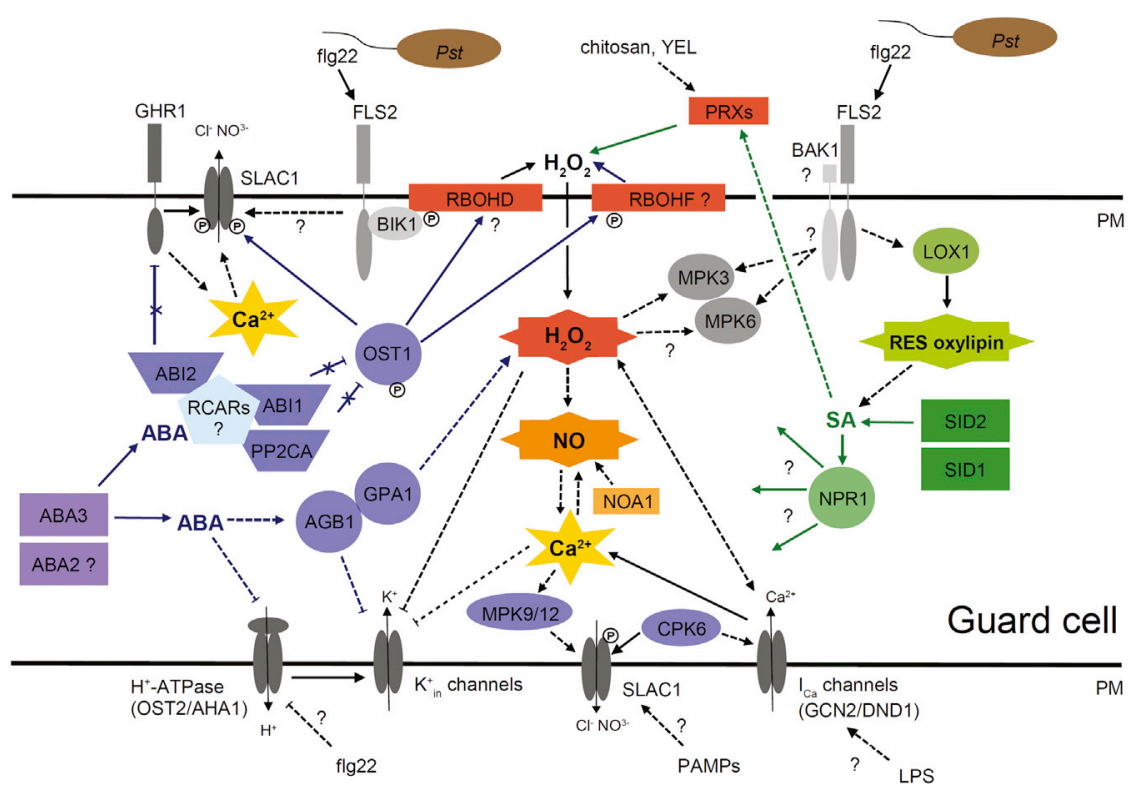

Figure 2. SA and ABA Signaling Pathways Positively Regulate Stomatal Immunity. During PAMP-triggered stomatal closure, $\mathrm{H}_{2} \mathrm{O}_{2}$ is produced by the NADPH oxidase RBOHD or by apoplastic peroxidases (PRXs). RBOHF and PRXs are respectively required for ABA- and SA-mediated ROS production. Together with RBOHF, RBOHD has an additive effect on ABAmediated closure. Downstream secondary messengers such as $\mathrm{H}_{2} \mathrm{O}_{2}, \mathrm{NO}$, and $\mathrm{Ca}^{2+}$ as well as inward calcium $\mathrm{I}_{\mathrm{Ca}}$ channels, S-type anion efflux channels (notably SLAC1), and inward $\mathrm{K}^{+}\left(\mathrm{K}^{+}\right.$in $)$ channels are largely shared by PAMPs, ABA, and $S A$ signaling pathways in guard cells. The accumulation of cytoplasmic $\mathrm{H}_{2} \mathrm{O}_{2}$ induces $\mathrm{NO}$ production mediated by NOA1. PAMPs and $\mathrm{H}_{2} \mathrm{O}_{2}$ can directly activate $\mathrm{I}_{\mathrm{Ca}}$ channels, such as GCN2/ DND1, leading to transient elevations of $\left[\mathrm{Ca}^{2+}\right]_{\text {cyt }}$. Importantly, SA seems not to induce $\left[\mathrm{Ca}^{2+}\right]_{\text {cyt }}$ elevations. Increases in $\left[\mathrm{Ca}^{2+}\right]_{\text {cyt }}$ and $\mathrm{H}_{2} \mathrm{O}_{2}$ accumulation inhibit $\mathrm{K}^{+}$in channels and also activate SLAC1. Whether PAMPs can directly activate SLAC1 in guard cells independently of $\mathrm{H}_{2} \mathrm{O}_{2}$ production or calcium elevations is unknown. flg22 may inhibit the plasma membrane $\mathrm{H}^{+}$-ATPase (AHA1/OST2) by (de)phosphorylation. Elements of ABA or $\mathrm{SA}$ signaling pathways involved in stomatal immunity are depicted in blue and green, respectively. Under resting conditions, the protein phosphatases $2 \mathrm{C}$ PP2CA, ABI1, and ABI2 negatively regulate ABA signaling. When the ABA level increases, the inhibitory effect of PP2Cs is released by their binding to the ABA-RCAR/PYR/PYL (RCARs) complexes, allowing OST1 to activate downstream targets such as SLAC1 and possibly RBOHF (see text for details). ABA signaling elements GPA1 and AGB1 inhibit $\mathrm{K}^{+}$in channels, and GPA1 activates $\mathrm{H}_{2} \mathrm{O}_{2}$ production in guard cells. Acting downstream of $\mathrm{H}_{2} \mathrm{O}_{2}$ production, MPK9 and MPK12 redundantly activate S-type anion channels, and CPK6 phosphorylates and activates SLAC1. ABI2 inhibits SLAC1 activation by the LRR-RK GRH1 which is also involved in SA-mediated stomatal closure. SA biosynthesis mediated by SID2/ICS1 and SID1/EDS5 and the SA signaling regulator NPR1 are required for stomatal defense responses. However, downstream components in guard cells regulated by NPR1 remain to be identified. RES oxylipins produced by LOX1 require SA to close stomata. MPK3 and MPK6 act upstream or independently of RES oxylipins, and are activated by PAMPs and $\mathrm{H}_{2} \mathrm{O}_{2}$. Arrowheads designate activation and bars show inhibition. Dashed lines indicate indirect connections, filled lines show direct interactions, and question marks denote hypothetical connections that might not occur in guard cells.

biological effects of $\mathrm{NO}$ is to regulate protein activities by $S$-nitrosylation. Interestingly, S-nitrosylation of RBOHD was shown to abolish its activity, suggesting the existence of a negative feedback regulation of NADPH oxidases by NO (Yun et al., 2011).

Some evidence suggests that calcium $\left(\mathrm{Ca}^{2+}\right)$ flux into plant cells occurs both upstream and downstream of ROS generation and that $\mathrm{Ca}^{2+}$ works together with $\mathrm{NO}$ to regulate plant innate immune response to pathogens (reviewed in Torres, 2010; Jeandroz et al., 2013). In Arabidopsis mesophyll cells, DAMPs and MAMPs activate calcium channels, leading to a transient increase in cytosolic calcium concentration $\left[\mathrm{Ca}^{2+}\right]_{\text {cyt }}$ (Jeworutzki et al., 2010; Krol et al., 2010). In Arabidopsis guard cells, YEL and chitosan activate a hyperpolarization-activated inward $\mathrm{Ca}^{2+}$ current $\left(\mathrm{I}_{\mathrm{Ca}}\right)$ and induce transient elevations in $\left[\mathrm{Ca}^{2+}\right]_{\mathrm{cyt}}$ that require the presence of extracellular $\mathrm{Ca}^{2+}$ (Figure 2; Klusener et al., 2002; Khokon et al., 2010b). It was further confirmed that the $\mathrm{Ca}^{2+}$ chelator EGTA inhibits YEL-mediated stomatal closure. Interestingly, YEL-induced $\left[\mathrm{Ca}^{2+}\right]_{\text {cyt }}$ oscillations depend on PRXs-generated ROS production and are independent of RBOHD/F (Khokon et al., 2010b).

It was shown that EGTA or $\mathrm{Gd}^{3+}$, a blocker of $\mathrm{I}_{\mathrm{Ca}}$ currents, substantially reduces LPS-activated NO generation in Arabidopsis guard cells (Ali et al., 2007). LPS activates $\mathrm{I}_{\mathrm{Ca}}$ currents in guard cells only when the action of calmodulin (CaM) in the cytosol is blocked by the CaM antagonist W7. The Arabidopsis
CYCLIC NUCLEOTIDE GATED CHANNEL2/DEFENSE NO DEATH1 (CNGC2/DND1) mediates cAMP-activated $\mathrm{I}_{\mathrm{Ca}}$ currents, and the dnd 1 mutant is partially impaired in LPS-induced NO and $\mathrm{H}_{2} \mathrm{O}_{2}$ production (Figure 2; Ali et al., 2007; Ma et al., 2009). Furthermore, LPS-mediated NO production in guard cells is inhibited by the CaM antagonist W7 and is dependent on $\mathrm{Ca}^{2+}$ / CaM-like 24 (CML24), a putative $\mathrm{Ca}^{2+}$-binding sensor protein (Ali et al., 2007; Ma et al., 2008). Further work is needed to understand the role of CNGC2 and CML24 in stomatal defense responses.

\section{Pathogen- and PAMP-Induced Activation of Plasma Membrane Ion Channels}

Among the earliest events induced by the perception of PAMPs in plants are changes in ion transport activities at the plasma membrane. In Arabidopsis mesophyll cells, flg22 and elf18 perception triggers a rapid increase in extracellular pH (Felix et al., 1999; Kunze et al., 2004). Moreover, flg22- and elf18-triggered depolarization of the plasma membrane is accompanied by the efflux of $\mathrm{Cl}^{-}$and $\mathrm{K}^{+}$as well as the influx of $\mathrm{H}^{+}$(Jeworutzki et al., 2010; Krol et al., 2010). It was postulated that PAMPs activate plasma membrane anion channels in mesophyll cells through a $\mathrm{Ca}^{2+}$ dependent mechanism and independently of the NADPH oxidases RBOHD and RBOHF.

Electrophysiological studies on PAMP-triggered changes in membrane polarization and regulation of ion channels using the 
Molecular Plant

guard cell as a model system are more scarce. It has been demonstrated that PAMP-triggered stomatal movements involve the regulation of potassium $\left(\mathrm{K}^{+}\right)$channels in Arabidopsis guard cells (Figure 2; Zhang et al., 2008; Ye et al., 2013). flg22 inhibits $\mathrm{K}^{+}$in currents and prolonged exposure to flg22 leads to an inhibition of $\mathrm{K}^{+}$out currents. FLS2 is required for flg22 inhibition of inward and outward $\mathrm{K}^{+}$currents (Zhang et al., 2008). It was demonstrated in barley guard cells that the apoplastic $\mathrm{pH}$ rapidly increases after infection with barley mildew (Blumeria graminis) or chitin treatment (Felle et al., 2004). Moreover, barley mildew and chitosan inhibit light-induced plasma membrane hyperpolarization and activate S-type anion channels (Koers et al., 2011). The resulting membrane depolarization promotes $\mathrm{K}^{+}$extrusion and stomatal closure. Recent patchclamp analyses indicate that YEL activates guard cell S-type anion channels and inhibits $\mathrm{K}^{+}$in channels (Ye et al., 2013). Interestingly, it was shown recently that mutation in the SLOWTYPE ANION CHANNEL1 (SLAC1) impairs flg22-mediated stomatal closure (Montillet et al., 2013).

Plasma membrane $\mathrm{H}^{+}$-ATPases play a major role in initiating stomatal opening by driving the hyperpolarization of the plasma membrane. The plasma membrane $\mathrm{H}^{+}$-ATPase AHA1 is expressed in Arabidopsis guard cells, and constitutive activation of AHA1 in the ost2-1D and ost2-2D dominant mutants completely prevents $\mathrm{ABA}-, \mathrm{H}_{2} \mathrm{O}_{2}-\mathrm{NO}$-, and $\mathrm{Ca}^{2+}$-mediated stomatal closure, and also impairs stomatal closure in response to flg22, LPS, and Pst DC3000 (Merlot et al., 2007; Liu et al., 2009). As a consequence, ost2-1D and ost2-2D mutants are more susceptible to spray-inoculated Pst DC3000 but are as susceptible as WT plants after syringe-inoculation (Liu et al., 2009). Interestingly, activation of AHA1 also leads to inhibition of flg22-triggered ROS burst (Keinath et al., 2010). Moreover, flg22 treatment induces phosphorylation changes in AHA1 and AHA2 (Nühse et al., 2007). Further research is needed to determine if $\mathrm{H}^{+}$-ATPase activity is inhibited by (de) phosphorylation after PAMP perception.

\section{HORMONAL SIGNALING PATHWAYS INVOLVED IN STOMATAL IMMUNITY}

\section{Abscisic Acid, a Major Regulator of Stomatal Immunity?}

Many plant hormones play a role in plant defense against pathogens (see for review Robert-Seilaniantz et al., 2011). The mode of action of $A B A$ in plant defense responses greatly depends on the pathosystem studied as well as the stage of infection (Ton et al., 2009). In the case of infection by Pst bacteria, ABA promotes resistance at the pre-invasive stage such as stomatal immunity while it enhances susceptibility at post-invasive stages in the apoplast (Melotto et al., 2006; de Torres-Zabala et al., 2007; Zeng and He, 2010; Lim et al., 2014). As already mentioned, several studies suggest that PAMP-induced stomatal closure shares a common signaling pathway with $A B A-$ induced stomatal closure such as $\mathrm{H}_{2} \mathrm{O}_{2}$ and $\mathrm{NO}$ accumulation, increase in cytosolic calcium, activation of S-type anion channels, and inhibition of $\mathrm{K}^{+}$in channels (Figure 2; Klusener et al., 2002; Melotto et al., 2006; Desikan et al., 2008; Zhang et al., 2008). Moreover, several components of the ABA biosynthesis and signaling pathways were shown to influence stomatal defense responses (Melotto et al., 2006; Zeng and He, 2010).

\section{Signaling Pathways Regulating Stomatal Immunity}

Importantly, the action of ABA on stomatal immunity seems to occur downstream of the PPR complex because fls2, bik1, and rbohD mutants exhibit WT stomatal closure in response to exogenous ABA (Zeng and He, 2010; Macho et al., 2012; Li et al., 2014).

$A B A$ is required for bacteria and PAMP-induced stomatal closure (Melotto et al., 2006; Du et al., 2014). Reduced level of ABA in the Arabidopsis ABA-deficient mutant aba3-1 compromises PAMPand Pst DC3000-induced stomatal closure, and ABA3 is required for resistance to surface-inoculated COR-deficient Pst DC3118 bacteria (Melotto et al., 2006). Similarly, Pst DC3000-induced stomatal closure is compromised in the ABA-deficient tomato notabilis (not) mutant affecting the ABA synthesis NCED1 gene, and not plants were more susceptible to dip-inoculated CORdeficient but not WT Pst bacteria (Du et al., 2014). Moreover, the NAC transcription factor (TF) JASMONIC ACID2 (JA2) positively regulates $A B A$ biosynthesis in tomato through direct activation of NCED1 expression. Like NCED1, JA2 is involved in flg22- and Pst-induced stomatal closure and in resistance to surface-inoculated COR-deficient Pst bacteria. Therefore, this recent finding indicates that the activation of $A B A$ biosynthesis by the JA2/NCED1 transcriptional module is crucial for stomatal immunity (Du et al., 2014).

The core $A B A$ signaling components include the ABA receptors PYRABACTIN RESISTANCE1/PYR1-LIKE/REGULATORY COMPONENTS OF ABA RECEPTOR (PYR1/PYL/RCAR), a group of protein phosphatases $2 \mathrm{C}$ (PP2C), and three SNF1-related protein kinases (Joshi-Saha et al., 2011). Under normal conditions, the OPEN STOMATA1/SNF1-RELATED PROTEIN KINASE 2.6 (OST1/SnRK2.6) is inhibited by the PP2Cs ABA-INSENSITIVE1 $(A B I 1)$ and $A B I 2$, which are negative regulators of the $A B A$ signaling pathway. Under stress conditions, PYR/PYL/RCAR binds to the accumulated ABA and in turn interacts with and inhibits PP2Cs, thus releasing the inhibition of OST1 by PP2Cs (Joshi-Saha et al., 2011). OST1 directly phosphorylates and activates SLAC1, and can also phosphorylate RBOHF (Geiger et al., 2009; Lee et al., 2009; Sirichandra et al., 2009a). It was shown that OST1 and $A B I 1$ act upstream and $A B I 2$ acts downstream of ROS production in ABA-mediated stomatal closure (Murata et al., 2001; Mustilli et al., 2002). Importantly, the ost1-2 mutant is defective in flg22 and LPS-mediated stomatal closure and is more susceptible to COR-deficient bacteria (Melotto et al., 2006; Zeng et al., 2011). OST1 is also required for stomatal immunity against $E$. coli and Salmonella bacteria (Roy et al., 2013). In addition, it was shown that stomata of the dominant hypermorphic mutant abi1-1 are unable to close upon treatment with COR-deficient Pst DC3118 bacteria (Schellenberg et al., 2010). Interestingly, LecRK-V.5, a negative regulator of stomatal immunity, inhibits $A B A$ signaling upstream of ROS production. The partially closed stomatal phenotype observed in the lecrk-V.5-1 mutant can be reverted by the abi1-1 and abi2-1 mutations (Desclos-Theveniau et al., 2012). A recent study indicates that besides $A B I 1$ and $A B I 2, R C A R 3 /$ PYL8 interacts with PP2CA, and overexpression of PP2CA induces partial defects in Pst DC3000-mediated stomatal closure (Lim et al., 2014). Altogether, it seems that the "core" ABA signaling pathway RCAR/PP2C/OST1 is involved in stomatal defenses (Figure 2). Further genetic analyses would add more clues on possible redundancies or specificities within each 
RCAR, PPC2, or SnRK2 family in the regulation of stomatal immunity.

The $\mathrm{Ga}$ and $\mathrm{G} \beta$ subunits, GPA1 and AGB1, are other common elements in PTI and ABA signaling in guard cells. Inhibition of $\mathrm{K}^{+}$in currents and stomatal opening by ABA is impaired in gpa 1 and agb1 mutants, and GPA1 acts upstream of ROS production in ABA signaling (Wang et al., 2001; Fan et al., 2008; Zhang et al., 2011). Importantly, GPA1 is also involved in flg22 inhibition of stomatal opening as well as in stomatal closure induced by WT or COR-deficient Pst bacteria (Zhang et al., 2008; Zeng and $\mathrm{He}$, 2010). Like the fls2 mutant, gpa1-3 plants are highly susceptible to COR-deficient Pst strain when surface inoculated but not when bacteria are directly infiltrated in the apoplast (Zeng and $\mathrm{He}, 2010)$. Moreover, it was recently shown that both GPA1 and AGB1 are important in stomatal closure induced by the non-host bacteria $P$ ta and in resistance to surface-inoculated Pta and virulent Psm bacteria (Lee et al., 2013). Thus, GPA1 and AGB1 are important players in stomatal defenses against bacteria.

Although a number of reports indicate that several components of the ABA pathway are implicated in stomatal defense responses to bacteria, two recent studies question the role of $A B A$ as a major regulator in stomatal immunity (Issak et al., 2013; Montillet et al., 2013). It was suggested that ABA does not directly control PAMPinduced stomatal closure but rather contributes to potentiate stomatal response to biotic stimuli. Indeed, YEL- and chitosaninduced stomatal closure is not impaired in the ABA-deficient mutant aba2-2 or in plants treated with fluridon, an inhibitor of ABA biosynthesis (Issak et al., 2013). Moreover, ost1-2 and aba2-1 mutants were only partially defective in flg22-triggered stomatal closure, and ost1-2 stomata did close at high flg22 concentration (Montillet et al., 2013). In-gel kinase assay experiments showed that OST1 is not activated by flg22 in cell suspension culture, suggesting that OST1 is not required for PTI. However, analysis of OST1 activation by PAMPs specifically in guard cells would be more relevant, as OST1 is more highly expressed in guard cells than in mesophyll cells (Mustilli et al., 2002). Moreover, OST1 is likely a master regulator of stomatal response not only to $\mathrm{ABA}$ but also to multiple environmental stimuli (Merilo et al., 2013). OST1 is known to interact with RBOHF and RBOHD and, more importantly, to activate SLAC1, which is involved in PAMP-triggered stomatal closure (Geiger et al., 2009; Sirichandra et al., 2009a; Acharya et al., 2013; Montillet et al., 2013). Differences in plant growth conditions such as the temperature, relative humidity, or light intensity may explain the conflicting results obtained on the importance of OST1 and ABA biosynthesis genes in PAMP-triggered immunity. Notably, high relative humidity makes the stomata less responsive to ABA and flg22 (Pantin et al., 2013; Roy et al., 2013). Nevertheless, it was recently shown that activation of ABA signaling also counteracts bacteria-mediated stomatal reopening (Desclos-Theveniau et al., 2012; Lim et al., 2014). Therefore, these studies indicate that $A B A$ is one of the key hormones implicated in stomatal immunity.

\section{Salicylic Acid, the Second Key Regulator of Stomatal Immunity}

The plant hormone SA plays a prominent role in modulating plant immune responses against diverse pathogens, and the transcriptional co-activator NONEXPRESSOR OF PR GENES1 (NPR1) was shown to be a master regulator of SA signaling pathway (Robert-Seilaniantz et al., 2011).

In Vicia faba and Arabidopsis, SA can induce stomatal closure, albeit at higher concentration (over $10 \mu \mathrm{M}$ ) compared with ABA (Mori et al., 2001; Zeng and He, 2010; Khokon et al., 2011). SAmediated stomatal closure involves PRX-mediated extracellular ROS production (Figure 2; Mori et al., 2001; Khokon et al., 2011). In addition, NPR1 is required for SA-induced stomatal closure (Zeng and He, 2010). Importantly, SA-mediated ROS production and stomatal closure are not impaired by DPI or in rbohD rbohF double mutant (Khokon et al., 2011). NO production is also necessary for SA-mediated stomatal closure, and occurs downstream of ROS accumulation (Hao et al., 2010; Khokon et al., 2011). SA-mediated stomatal closure and NO production are dependent of NOA1 and the nitrate reductases NIA1 and NIA2 (Hao et al., 2010; Sun et al., 2010). Contrary to ABA, SA does not induce $\mathrm{Ca}^{2+}$ oscillations in Arabidopsis guard cells but extracellular $\mathrm{Ca}^{2+}$ seems to be required for SA-mediated stomatal closure. Like ABA, SA suppresses $\mathrm{K}^{+}$in channel activity (Khokon et al., 2011). Notably, PRXs are not required for ABAinduced ROS production and stomatal closure (Khokon et al., 2010b). Thus, ABA and SA signaling pathways leading to stomatal closure seem to be independent at least upstream of ROS accumulation.

Bacteria and PAMP-induced stomatal closure in Arabidopsis depends on SA synthesis and signaling pathways. Pst DC3000and LPS-induced stomatal closure is compromised in plants with reduced SA levels such as SA-deficient nahG transgenic plants and the SA biosynthesis mutant eds16-2/sid2-2 affecting the ISOCHORISMATE SYNTHASE1 (ICS1) gene (Melotto et al., 2006). It was also shown that EDS5/SID1/SCORD3, a putative transporter protein required for SA biosynthesis, and NPR1 are required for stomatal closure in response to COR-deficient Pst bacteria (Zeng and He, 2010; Zeng et al., 2011). As a consequence, npr1-1, eds16-2, eds5/scord3 mutants, and nahG transgenic plants are more susceptible to surfaceinoculated COR-deficient Pst DC3118 (Melotto et al., 2006; Zeng and He, 2010; Zeng et al., 2011). Interestingly, of the six scord mutants defective in stomatal closure in response to COR-deficient bacteria, four (including scord3) contain low basal and bacterium-induced SA levels, suggesting that SA is crucial for stomatal defenses (Zeng et al., 2011). Among these, scord6 and scord8 seem preferentially impaired in SA-mediated stomatal closure. The identification of the genes affected by the scord 6 and scord8 mutations is of particular interest, as NPR1 is the only SA signaling component known to be implicated in stomatal immunity.

\section{Possible Interactions between ABA and SA Signaling Pathways in Stomatal Defenses}

EDS5/SID1, SID2, and NPR1 are not involved in ABA-induced stomatal closure, indicating that $A B A$ signaling in guard cells does not require normal endogenous SA level and that NPR1 functions upstream or independently of ABA (Zeng and $\mathrm{He}$, 2010; Zeng et al., 2011; Montillet et al., 2013). Interestingly, the aba2-1 mutant is impaired in stomatal closure induced by SA at $20 \mu \mathrm{M}$, suggesting that normal $\mathrm{ABA}$ level in plant is required for 
Molecular Plant

both SA- and PAMP-triggered stomatal closure (Zeng and $\mathrm{He}$, 2010). From this epistatis analysis, it was suggested that $S A$ signaling acts upstream of $A B A$ signaling in bacteria-induced stomatal closure. However, SA was recently found to induce stomatal closure in aba2-2 plants, albeit at high concentration $(200 \mu \mathrm{M})$, suggesting that endogenous $A B A$ is not involved in SA-induced stomatal closure (Issak et al., 2013). Moreover, the ABA signaling components RBOHF and LecRK-V.5 are not required for $S A$-induced stomatal closure, suggesting that $A B A$ and SA signaling pathways are independent (Kwak et al., 2003: Khokon et al., 2011; Desclos-Theveniau et al., 2012). The analysis of OST1 and GPA1 function in SA signaling in guard cells would shed more light on $A B A$ and $S A$ crosstalk in stomatal immunity.

Recently, a novel oxylipin signaling pathway regulating stomatal immunity in an SA-dependent and ABA-independent manner has been elucidated (Montillet et al., 2013). The guard cell-expressed LIPOXYGENASE1 (LOX1) gene is required for flg22- and Pst DC3000-triggered stomatal closure and for resistance to spray-inoculated Pst DC3000 (Figure 2). Moreover, both LOX1 substrates polyunsaturated fatty acids and LOX1 products fatty acid hydroperoxides, and reactive electrophile species oxylipin (RES oxylipin), induce stomatal closure. RES oxylipin-mediated stomatal closure requires SID1 and SID2 but not OST1 and ABA2, and lox1 mutants exhibit WT stomatal closure in response to $S A$ and $A B A$, suggesting that LOX1 acts independently of $A B A$ and upstream of the $S A$ signaling pathway.

The aforementioned reports strongly suggest that ABA and SA signaling pathways independently control PAMP-triggered stomatal closure. On the other hand, other studies indicate that $\mathrm{SA}$ and $\mathrm{ABA}$ signaling pathways can converge to control stomatal immunity. The scord7 mutant deficient in stomatal defense to COR-deficient Pst bacteria shows defects in ABA- and SAmediated stomatal closure, indicating that SCORD7 probably interferes with a late step common to both SA and ABA signaling pathways (Zeng et al., 2011). Moreover, the LRR-RLK GUARD CELL HYDROGEN PEROXIDE-RESISTANT1 (GHR1) was shown to positively regulate flg22-, ABA-, SA-, and $\mathrm{H}_{2} \mathrm{O}_{2}$-mediated stomatal closure (Hua et al., 2012). GHR1 acts downstream of ROS production, phosphorylates and activates SLAC1, and is important for $\mathrm{ABA}$ and $\mathrm{H}_{2} \mathrm{O}_{2}$ activation of inward $\mathrm{Ca}^{2+}$ currents and S-type anion currents. Furthermore, GHR1 interacts with $A B I 2$ and GHR1-mediated SLAC1 activation is inhibited by $A B I 2$ but not by $A B I 1$. This report suggests that GHR1 participates in crosstalk between flg22, ABA, and SA by activating SLAC1.

In summary, during stomatal immunity the ABA and SA signaling pathways seem independent upstream of ROS production but interconnected downstream at the level of ion channels (Figure 2). However, more evidence is needed to verify this hypothesis.

\section{Role of the Protein Kinases MAPK and CDPK in Stomatal} Defense

MAPKs are known to play a role in stomatal movements in response to ABA and $\mathrm{H}_{2} \mathrm{O}_{2}$ (Wang and Song, 2008). Guard cellspecific suppression of MPK3 expression leads to partial defects
Signaling Pathways Regulating Stomatal Immunity

in ABA inhibition of light-induced stomatal opening and $\mathrm{H}_{2} \mathrm{O}_{2}$ mediated stomatal closure (Gudesblat et al., 2007). MPK3 is also important for bacteria- and LPS-triggered stomatal closure and resistance to dip-inoculated COR-deficient Pst DC3118 (Figure 2; Gudesblat et al., 2009). Moreover, MPK3 and MPK6 are positive regulators of flg22-triggered stomatal closure, whereas MPK4 seems not to be involved in stomatal immunity (Berriri et al., 2012; Montillet et al., 2013). Notably, MPK3 and MPK6 are not involved in ABA-mediated stomatal closure (Gudesblat et al., 2007; Montillet et al., 2013), pointing out the difference from the signaling network regulating ABA inhibition of stomatal opening, which is also important for stomatal immunity as observed for GPA1 and AGB1 (Zhang et al., 2008; Zeng and He, 2010; Lee et al., 2013). It was suggested that MPK3 may act downstream of $\mathrm{H}_{2} \mathrm{O}_{2}$ in PAMP-triggered stomatal closure (Gudesblat et al., 2009; Montillet et al., 2013). On the other hand, MPK3 and MPK6 activation by flg22 is not affected in the rbohD mutant, suggesting that these MAPK act upstream or independently of the RBOHD-mediated oxidative burst (Zhang et al., 2007; Macho et al., 2012).

The MPK9 and MPK12 act redundantly as positive regulators of ABA- and ROS-mediated stomatal closure upstream of anion channels and, presumably, downstream of ROS production and $\left[\mathrm{Ca}^{2+}\right]_{\text {cyt }}$ oscillations (Jammes et al., 2009). MPK9/MPK12 also function in chitosan- and YEL-induced stomatal closure probably downstream of ROS production and $\left[\mathrm{Ca}^{2+}\right]_{\mathrm{cyt}}$ oscillations (Figure 2; Salam et al., 2012; Salam et al., 2013). Moreover, the mpk9 mpk12 double mutant is more susceptible to sprayinoculated Pst DC3000 (Jammes et al., 2011). Intriguingly, MPK9 and MPK12 seem not to be involved in flg22-mediated stomatal closure (Montillet et al., 2013). More research is definitely needed to clarify the function of MPK3, MPK6, MPK9, and MPK12 in guard cell signaling in response to pathogens.

In Arabidopsis, the calcium-dependent protein kinases (CDPKs) CPK5, CPK6, and CPK11 are redundant positive regulators of the flg22-triggered oxidative burst and apoplastic resistance to Pst DC3000 (Boudsocq et al., 2010). However, except for CPK6 (Figure 2), little is known about CDPK function in stomatal defense responses. It has been demonstrated that CPK6 functions in ABA-induced stomatal closure by activating S-type anion and $\mathrm{I}_{\mathrm{Ca}}$ channels independently of $\mathrm{H}_{2} \mathrm{O}_{2}$ production (Mori et al., 2006). In addition, CPK6 phosphorylates and activates SLAC1 expressed in Xenopus oocytes (Brandt et al., 2012). Recently, a role for CPK6 in YEL-triggered stomatal closure has been uncovered (Ye et al., 2013). In response to YEL, CPK6 activates the $\mathrm{I}_{\mathrm{Ca}}$ and $\mathrm{S}$-type anion channels and inhibits $\mathrm{K}^{+}$in channels. These reports suggest that CPK6 acts as a positive regulator integrating signaling pathways for stomatal response to both abiotic and biotic stresses.

\section{Ethylene, Another Phytohormone that Potentiates Stomatal Immunity}

The gaseous hormone ethylene is produced by the plant during PAMP-triggered immunity (Felix et al., 1999). It was shown that the ethylene signaling components ETHYLENE RECEPTOR1 (ETR1) and ETHYLENE-INSENSITIVE2 (EIN2) participate in flg22-elicited oxidative burst in seedlings and in accumulation of FLS2 transcripts and proteins (Mersmann et al., 2010). 
Contrasting effects of ethylene on stomatal closure were described in Arabidopsis depending on the method used. Ethylene does not close stomata and inhibits ABA-induced stomatal closure on epidermal peels, while on intact leaves ethylene promotes stomatal closure (Tanaka et al., 2005; Desikan et al., 2006). Both ETR1 and EIN2 are required for ethylene- and $\mathrm{H}_{2} \mathrm{O}_{2}$-induced stomatal closure, and ETR1 but not EIN2 is involved in ethylene-induced $\mathrm{H}_{2} \mathrm{O}_{2}$ production, suggesting that ETR1 also acts upstream of ROS synthesis (Desikan et al., 2005; Desikan et al., 2006). Remarkably, ETR1 and EIN2 are also required for resistance to the disarmed Pst DC3000 $\triangle A v r P t o / \triangle A v r P t o B$ strain at an early stage of infection, as well as for bacteria- and flg22-mediated stomatal closure (Mersmann et al., 2010). Although RBOHF, but not RBOHD, mediates ethylene-induced ROS production and stomatal closure, RBOHF seems not to be involved in flg22-mediated stomatal closure (Desikan et al., 2006; Mersmann et al., 2010).

The ARABIDOPSIS HISTIDINE KINASE5 (AHK5) contributes to ethylene-induced ROS production and stomatal closure (Desikan et al., 2008). Interestingly, AHK5 participates in plant resistance to surface-inoculated Pst DC3000, in Pst DC3000and flg22-induced stomatal closure, and in flg22-induced $\mathrm{H}_{2} \mathrm{O}_{2}-$ production (Desikan et al., 2008; Pham et al., 2012). Surprisingly, ahk5 mutants were not affected in elf26-mediated ROS production and stomatal closure (Desikan et al., 2008). More detailed analysis demonstrated that AHK5 mediates $\mathrm{H}_{2} \mathrm{O}_{2}$ - and NO-mediated stomatal closure downstream of NO production. Importantly, ETR1, EIN2, and AHK5 are not required for ABA-mediated ROS production and stomatal closure (Desikan et al., 2006; Desikan et al., 2008). Thus, the control of stomatal immunity through components of the ethylene signaling pathway seems ABA independent, at least upstream of RBOHF-mediated ROS synthesis.

\section{BACTERIAL VIRULENCE FACTORS AND EFFECTORS AFFECTING STOMATAL IMMUNITY}

Plant pathogens have evolved virulence factors such as toxins or effectors to counteract stomatal defenses as a widespread strategy to gain entry into the leaves. Fungal virulence factors such as oxalate and fusicoccin are known to promote stomatal opening (Elmore and Coaker, 2011; Grimmer et al., 2012). The bacterial effector HopM1 and the virulence factor syringolin A, targeting the proteasome to modulate stomatal defenses, have been recently reviewed (McLachlan et al., 2014). We focus in this section on the recent findings describing the bacterial toxin coronatine, important for Pst-mediated inhibition of stomatal immunity.

\section{Activation of the Jasmonate Signaling Pathway by the Virulence Factor Coronatine}

The phytotoxin COR suppresses stomatal defense and is critical for successful Pst DC3000 virulence on host plants. The T3Sdefective hrcC mutant strain is not impaired in stomatal reopening or in increase in stomatal conductance, suggesting that Pst DC3000-mediated stomatal reopening is COR dependent and is independent of T3SS effectors (Melotto et al., 2006; Freeman and Beattie, 2009). Moreover, COR treatment is able to counteract flg22-, LPS-, and ABA-induced stomatal closure (Melotto et al., 2006). COR acts downstream or independently of NO accumulation in response to PAMPs or ABA and reverses the inhibitory effect of flg22 on $\mathrm{K}^{+}$in currents, but does not affect the flg22-mediated slow inhibition of $\mathrm{K}^{+}$out currents (Figure 3; Melotto et al., 2006; Zhang et al., 2008). It was shown that RIN4, a negative regulator of plant immunity expressed in guard cells, directly interacts with $\mathrm{AHA} 1$ and $\mathrm{AHA} 2$ and increases plasma membrane $\mathrm{H}^{+}$-ATPase activity (Liu et al., 2009). Importantly, RIN4 regulates Pst DC3000-mediated stomatal reopening and promotes susceptibility to spray-inoculated Pst DC3000. These results suggest that RIN4 probably mediates COR-dependent suppression of PAMP-triggered inhibition of inward $\mathrm{K}^{+}$currents via the activation of plasma membrane $\mathrm{H}^{+}$ATPase (Figure 3).

It is well known that COR activates the jasmonic acid (JA) signaling pathway to repress the SA signaling pathway (RobertSeilaniantz et al., 2011). COR is structurally similar to the biologically active JA-isoleucine (JA-lle; Katsir et al., 2008). However, the role of JA in stomatal movements is still a matter of debate, as conflicting results have been obtained. It was shown that methyl-JA (MeJA) induces stomatal closure (Suhita et al., 2004; Munemasa et al., 2007; Desclos-Theveniau et al., 2012; Hua et al., 2012) while recently, Montillet et al. (2013) found that MeJA does not close stomata and instead reverses RES oxylipin- and flg22-mediated stomatal closure. Importantly, in morning glory (Ipomoea tricolor), COR and the biologically active JA-lle but not JA can open dark-closed stomata (Okada et al., 2009). Depending on concentrations used and plant growing conditions, exogenous applied MeJA, JA, and JA-lle may have contrasting effects on stomatal movements.

The virulence function of COR requires the CORONATINEINSENSITIVE1 (COI1), and both JA-lle and COR bind to the COI1 F-box protein of the Skp/Cullin/F-box complex (SCF ${ }^{\mathrm{CO} 1}$ ). COI1 and the MYC2 TF directly interact with JASMONATE ZIMdomain (JAZ) transcriptional repressors (Figure 3). Binding of JA-lle or COR to SCF ${ }^{\mathrm{CO} 11}$-JAZ complex promotes ubiquitination of JAZs, leading to their degradation by the $26 \mathrm{~S}$ proteasome. The release of MYC2 repression by JAZs facilitates activation of JA/COR-responsive genes (Robert-Seilaniantz et al., 2011). Expressed in guard cells, COI1 is required for Pst DC3000mediated stomatal reopening as well as COR inhibition of ABAmediated and RES oxylipin-mediated stomatal closure (Melotto et al., 2006; Zheng et al., 2012; Montillet et al., 2013). Likewise, the tomato JA-INSENSITIVE1 (JAI1), homologous to the Arabidopsis COI1, is implicated in Pst DC3000-mediated stomatal reopening and promotes susceptibility to surface-inoculated Pst DC3000 bacteria (Du et al., 2014).

Recently, it was shown that COR and Psm ES4326, but not CORdeficient $P s m$, activate the expression of three Arabidopsis NAC TF genes ANAC019, ANAC055, and ANAC072 (Zheng et al., 2012). Interestingly, COI1 and the MYC2 TF are required for Psm-induced expression of these NAC genes, and MYC2 directly binds to their promoters. Like coi1-3 mutant, the anac019/anac055/anac072 triple mutant is defective in CORmediated stomatal reopening and is more resistant to dipinoculated Psm ES4326. These three NAC TFs inhibit the accumulation of SA after Psm ES4326 challenge by repressing the 


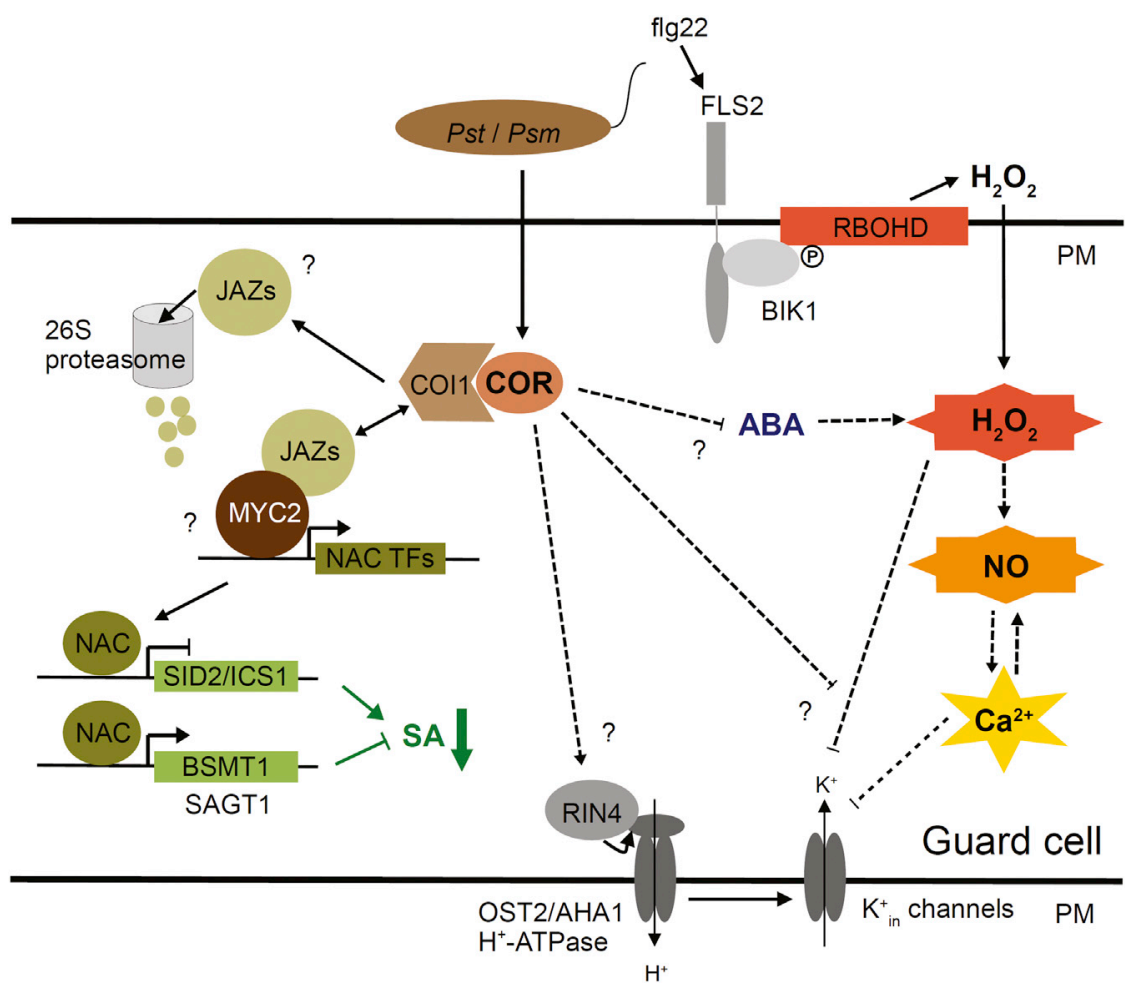

Figure 3. Coronatine Suppresses Stomatal Immunity by Activating the Jasmonate Signaling Pathway.

Coronatine (COR) acts downstream of $\mathrm{H}_{2} \mathrm{O}_{2}$ and $\mathrm{NO}$ production in guard cells and reverts PAMP-mediated inhibition of inward $\mathrm{K}^{+}\left(\mathrm{K}^{+}\right.$in $)$ currents, possibly by activating the $\mathrm{H}^{+}$-ATPase through RIN4. Alternatively $\mathrm{COR}$ can inhibit the ABA signaling pathway, probably downstream of $\mathrm{H}_{2} \mathrm{O}_{2}$ or $\mathrm{Ca}^{2+}$ elevations. JAZ proteins are transcriptional repressors of JA responsive genes by direct binding to the MYC transcription factor (TF). Binding of COR to COl1 increases its affinity toward JAZ and the $\mathrm{SCF}^{\mathrm{CO} 11}$ ubiquitin-ligase complex (not shown here) and catalyzes the ubiquitination of JAZs for their degradation by the 26S proteasome. JAZ inhibitory effects are then relieved and MYC can directly activate the expression of ANAC019, ANAC055, and ANAC072 (NAC TFs) genes involved in CORmediated suppression of bacterium-induced stomatal closure. In turn, NAC TFs repress the expression of the $\mathrm{SA}$ biosynthesis gene SID2/ICS1 and activate the expression of SA metabolism genes BSMT1 and SAGT1. The resulting decrease in SA level might release stomatal closure induced by PAMPs. However, the role of MYC2 and JAZ TFs in bacterium-mediated stomatal reopening is not yet demonstrated. Arrowheads designate activation, bars show inhibition. Dashed lines indicate indirect connections, filled lines show direct interactions, and question marks denote hypothetical connections.

expression of the SA biosynthesis gene ICS1 and activating the expression of SA metabolism genes SA METHYL TRANSFERASE1 (BSMT1) and SA GLUCOSYLTRANSFERASE1 (SAGT1). Similarly, expression of the tomato homolog NAC TF JA2-like (JA2L) is induced by MeJA and COR in a JAI1/COI1dependent manner (Du et al., 2014). JA2L suppresses Pstinduced $S A$ accumulation through binding to the promoter of SA METHYL TRANSFERASE1 and 2 (SAMT1 and SAMT2) genes to activate their expression. Moreover, JA2L positively regulates COR-mediated stomatal reopening and promotes susceptibility to surface-inoculated Pst DC3000 bacteria (Du et al., 2014). Together, these findings suggest that COR represses $\mathrm{SA}$ accumulation through $\mathrm{SCF}^{\mathrm{CO} 11}$-mediated degradation of the JAZ proteins, resulting in the release of MYC (Figure 3). Then MYC2 directly activates NAC TFs, which differentially regulate the expression of ISC1, BSMT1, and SAGT1. The decrease in leaf SA content is probably sufficient to reverse PAMPtriggered stomatal closure.

Some studies indicate that activation of the ABA signaling pathway can inhibit COR-mediated stomatal opening, leading to resistance against $P s t$ bacteria. Activation of ABA signaling in lecrk-V.5 mutants compromises COR-mediated inhibition of bacteria- and PAMP-triggered stomatal closure (DesclosTheveniau et al., 2012). Similarly, enhanced ABA sensitivity in $R C A R 3$ and $R C A R 2$ overexpressing lines or pp2ca mutants blocks COR-mediated stomatal reopening during Pst DC3000 infection or after flg22 treatment (Lim et al., 2014). As a consequence, RCAR3 and RCAR2 overexpressing lines, and lecrk-V.5 and pp2ca mutants showed enhanced resistance to dip-inoculated Pst DC3000 bacteria (Desclos-Theveniau et al.,
2012; Lim et al., 2014). Moreover, it was shown recently that the LRR-RK IMPAIRED OOMYCETE SUSCEPTIBILITY1 (IOS1) associates with FLS2, EFR, and BAK1, and inhibits Pst DC3000-mediated reopening of stomata probably via the activation of PTI (Chen et al., 2014). However, a recent study showed that IOS1 down-regulates ABA signaling in stomata (Hok et al., 2014). Taken together, these results seem to contradict previous findings indicating that the activation of the $A B A$ signaling pathway impedes the COR-mediated suppression of PAMP-induced stomatal closure (Desclos-Theveniau et al., 2012; Lim et al., 2014). Nevertheless, it was suggested that ios1 allelic mutants exhibit different phenotypes toward ABA sensitivity (Hok et al., 2014). More research is needed to understand the molecular function of IOS1 in stomatal defense.

\section{Bacteria-Mediated Promotion of Stomatal Closure at Post-Invasive Stage to Avoid Water Stress}

The COR-mediated increase in stomatal conductance is only transient, and a rapid decrease in stomatal conductance was observed at 5-7 hpi with Pst DC3000 (Freeman and Beattie, 2009). As water potential is important for Pst DC3000 survival and multiplication in the apoplast (Wright and Beattie, 2004), it was suggested that following successful entry into the leaves, bacteria may have developed mechanisms to induce a late stomatal closure for restricting water loss from the leaves and increasing water availability to bacteria (Freeman and Beattie, 2009; Beattie, 2011). Interestingly, the hrcC mutant experiences lower and less optimal water potentials in the apoplast compared with WT Pst (Wright and Beattie, 2004). Moreover, Pst hrcC does not induce a decrease in stomatal conductance between 5 and $7 \mathrm{hpi}$ as 
observed in WT strain Pst DC3000, suggesting that bacterial effectors are involved in the late stomatal closure for the control of host water status and optimal bacterial growth (Freeman and Beattie, 2009). It is known that T3SS-defective mutants are still able to produce coronatine. Notably, it has been reported that extended incubation with COR for 1 day induces ROS production in Arabidopsis seedlings (Camañes et al., 2012). As suggested, the long-lasting COR-mediated ROS accumulation may have the potential to induce stomatal closure.

It is well known that $A B A$ plays a negative role in plant defense at post-invasive stages of infection (Ton et al., 2009). The ABA biosynthesis mutant aao3 and ABA signaling mutants abi1-1 and abi2-1 are more resistant to syringe-inoculated Pst DC3000 (de Torres-Zabala et al., 2007). Moreover, ABA level in plant increases after inoculation with Pst DC3000 but not after inoculation with $P s t h r p A^{-}$, a mutant strain compromised in T3SS. Interestingly, inducible in planta expression of the T3SS effector AvrPtoB induces the expression of the ABA biosynthesis NCED3 gene and an increase in ABA level. However, until now the function of AvrPtoB in stomatal movements in response to ABA or other stimuli has not been evaluated. HopAM1, another effector, contributes to $P$. syringae virulence in moderately drought-stressed Arabidopsis plants in an ABI5-dependent manner (Goel et al., 2008). Notably, inducible expression of HopAM1 in Arabidopsis does not increase $A B A$ level in plant but induces ABA-hypersensitive phenotypes, including an enhanced ABA-induced stomatal closure. The identification of HopM1 targets involved in late Pst DC3000 induced stomatal closure will contribute to better understanding of this peculiar virulence mechanism. Moreover, host plants may have evolved strategies for stomatal opening to enhance water loss and restrict bacteria multiplication and survival in the apoplast. This unexplored research area in plant bacteria interactions clearly merits further investigation.

\section{CONCLUSIONS AND PERSPECTIVES}

As a potential gate of entry, stomata are one of the first lines of defense in the plant-pathogen battlefield. Many microbes and PAMPs can induce stomatal closure but surprisingly only one PPR, the flagellin receptor FLS2, has been shown to play a crucial role in stomatal defense against bacteria at least in the context of the Pst-Arabidopsis pathosystem. Although important for the microbe fitness, PAMPs are under host-driven selection pressure to evade recognition by PPRs. In turn, PPRs might undergo rapid evolution to cope with the increasing diversity of PAMPs. It is therefore important to understand the contribution of each PAMP/PPR couple in stomatal defense and plant disease resistance for different host-pathogen combinations. On the other hand, PPRs seem to function together within a molecular complex, as demonstrated with the interdependence of the receptors PEPR1 and FLS2 in mediating Pep3- and flg22-triggered ROS production. Moreover, even though highly controverted, FLS2 might function beyond flagellin perception as a multi-specific receptor (Monaghan and Zipfel, 2012). Some orphan PPRs such as LecRK-V.5 and LecRK-VI.2, for which the identity of extracellular ligand is still unknown, regulate stomatal closure in response to multiple PAMPs and influence plant defenses against different bacteria. The next challenge will be to identify more PPRs within the large RLK family and to assign ligands to these diverse PRRs.
The NADPH oxidase RBOHD and unknown apoplastic peroxidases are responsible for ROS production in guard cells after PAMP perception. The contribution of these two enzymatic sources in the overall ROS production, their synergistic effects, and their eventual interactions are still unknown and need further clarification. Downstream of PAMP perception, sequential events in the signaling pathway appear to be in the following order: $\mathrm{H}_{2} \mathrm{O}_{2}, \mathrm{NO}, \mathrm{Ca}^{2+}$, and then anion and $\mathrm{K}^{+}$channels. However, exceptions to this model have been demonstrated, such as the regulation of ROS production by the calcium channel GCN2/DND1 and the direct regulation of SLAC1 by the LRRRK GHR1. Moreover, in mesophyll cells, PAMP-triggered activation of anion channels seems independent of the NADPH oxidases RBOHD/F. An exciting possibility that needs to be further explored is that PPR complexes may directly regulate anion channels or $\mathrm{H}^{+}$-ATPase independently of ROS production and $\mathrm{Ca}^{2+}$ oscillations.

Many components of hormonal signaling pathways are directly implicated in or can influence stomatal immunity. Pathogenand PAMP-triggered stomatal closure shares common signaling elements with $\mathrm{ABA}, \mathrm{SA}$, and ethylene signaling pathways, at least downstream of ROS generation. Strangely, concerning the SA signaling pathway only NPR1 was identified as regulating stomatal immunity while many $A B A$ signaling components are known to affect stomatal defense responses. The characterization of NPR1 downstream targets is of crucial importance in better understanding the role of SA in stomatal immunity. Obviously, guard cells have evolved mechanisms to integrate biotic and abiotic signals with plant developmental status. Interestingly, two recent studies showed that the circadian regulators PCL1, CCA1, and LHY modulate stomatal immunity and demonstrated a feedback regulation of clock activity by PTI (Zhang et al., 2013; Korneli et al., 2014). The analysis of the role of plant growth hormones such as auxin and cytokinins in stomatal defenses would add more knowledge on how plants balance between plant development and activation of defense responses. The intricate network of signal transduction pathways connecting these different stomatal functions is far from being elucidated. Clearly, future research is needed to identify regulators implicated in crosstalk between stomatal immunity, guard cell hormonal signaling pathways, stomatal response to abiotic stresses, and integration of plant growth.

\section{FUNDING}

D.A. is supported by funding from the European Union's Seventh Framework Programme for research, technological development and demonstration under grant agreement no. GA-2010-267243 - PLANT FELLOWS. This work was supported by the National Research Foundation of Korea (NRF) grant funded by the Korea government (MSIP) (No. 2012R1A2A2A02014387).

\section{ACKNOWLEDGMENTS}

We apologize for not being able to review all relevant work due to space restrictions. We acknowledge two anonymous reviewers for their constructive feedback on the manuscript. No conflict of interest declared.

Received: September 6, 2014

Revised: October 25, 2014

Accepted: October 26, 2014

Published: November 3, 2014 


\section{REFERENCES}

Acharya, B., and Assmann, S. (2009). Hormone interactions in stomatal function. Plant Mol. Biol. 69:451-462.

Acharya, B.R., Jeon, B.W., Zhang, W., and Assmann, S.M. (2013). Open Stomata 1 (OST1) is limiting in abscisic acid responses of Arabidopsis guard cells. New Phytol. 200:1049-1063.

Ali, R., Ma, W., Lemtiri-Chlieh, F., Tsaltas, D., Leng, Q., von Bodman, S., and Berkowitz, G.A. (2007). Death don't have no mercy and neither does calcium: Arabidopsis CYCLIC NUCLEOTIDE GATED CHANNEL2 and innate immunity. Plant Cell 19:1081-1095.

Allan, A.C., and Fluhr, R. (1997). Two distinct sources of elicited reactive oxygen species in tobacco epidermal cells. Plant Cell 9:1559-1572.

Allègre, M., Héloir, M.C., Trouvelot, S., Daire, X., Pugin, A., Wendehenne, D., and Adrian, M. (2009). Are grapevine stomata involved in the elicitor-induced protection against downy mildew? Mol. Plant Microbe Interact. 22:977-986.

Arnaud, D., Desclos-Theveniau, M., and Zimmerli, L. (2012). Disease resistance to Pectobacterium carotovorum is negatively modulated by the Arabidopsis lectin receptor kinase LecRK-V.5. Plant Signal. Behav. 7:1070-1072.

Beattie, G.A. (2011). Water relations in the interaction of foliar bacterial pathogens with plants. Annu. Rev. Phytopathol. 49:533-555.

Berriri, S., Garcia, A.V., dit Frey, N.F., Rozhon, W., Pateyron, S., Leonhardt, N., Montillet, J.L., Leung, J., Hirt, H., and Colcombet, J. (2012). Constitutively active mitogen-activated protein kinase versions reveal functions of Arabidopsis MPK4 in pathogen defense signaling. Plant Cell 24:4281-4293.

Boller, T., and Felix, G. (2009). A renaissance of elicitors: perception of microbe-associated molecular patterns and danger signals by pattern-recognition receptors. Annu. Rev. Plant Biol. 60:379-406.

Boudsocq, M., Willmann, M.R., McCormack, M., Lee, H., Shan, L., He, P., Bush, J., Cheng, S.H., and Sheen, J. (2010). Differential innate immune signalling via $\mathrm{Ca}^{2+}$ sensor protein kinases. Nature 464:418-422.

Brandt, B., Brodsky, D.E., Xue, S., Negi, J., Iba, K., Kangasjarvi, J., Ghassemian, M., Stephan, A.B., Hu, H., and Schroeder, J.I. (2012). Reconstitution of abscisic acid activation of SLAC1 anion channel by CPK6 and OST1 kinases and branched ABI1 PP2C phosphatase action. Proc. Natl. Acad. Sci. USA 109:10593-10598.

Bright, J., Desikan, R., Hancock, J.T., Weir, I.S., and Neill, S.J. (2006). ABA-induced NO generation and stomatal closure in Arabidopsis are dependent on $\mathrm{H}_{2} \mathrm{O}_{2}$ synthesis. Plant J. 45:113-122.

Brooks, D.M., Hernandez-Guzman, G., Kloek, A.P., Alarcon-Chaidez, F., Sreedharan, A., Rangaswamy, V., Penaloza-Vazquez, A., Bender, C.L., and Kunkel, B.N. (2004). Identification and characterization of a well-defined series of coronatine biosynthetic mutants of Pseudomonas syringae pv. tomato DC3000. Mol. Plant Microbe Interact. 17:162-174.

Camañes, G., Pastor, V., Cerezo, M., García-Andrade, J., Vicedo, B., García-Agustín, P., and Flors, V. (2012). A deletion in NRT2.1 attenuates Pseudomonas syringae-induced hormonal perturbation, resulting in primed plant defenses. Plant Physiol. 158:1054-1066.

Chaouch, S., Queval, G., and Noctor, G. (2012). AtRbohF is a crucial modulator of defence-associated metabolism and a key actor in the interplay between intracellular oxidative stress and pathogenesis responses in Arabidopsis. Plant J. 69:613-627.

Chen, C.W., Panzeri, D., Yeh, Y.H., Kadota, Y., Huang, P.Y., Tao, C.N., Roux, M., Chien, S.C., Chin, T.C., Chu, P.W., et al. (2014). The Arabidopsis malectin-like leucine-rich repeat receptor-like kinase IOS1 associates with the pattern recognition receptors FLS2 and EFR and is critical for priming of pattern-triggered immunity. Plant Cell 26:3201-3219.

Molecular Plant 8, 566-581, April 2015 @ The Author 2015
Desclos-Theveniau, M., Arnaud, D., Huang, T.Y., Lin, G.J.C., Chen, W.Y., Lin, Y.C., and Zimmerli, L. (2012). The Arabidopsis lectin receptor kinase LecRK-V.5 represses stomatal immunity induced by Pseudomonas syringae pv. tomato DC3000. PLoS Pathog. 8:e1002513.

Desikan, R., Griffiths, R., Hancock, J., and Neill, S. (2002). A new role for an old enzyme: nitrate reductase-mediated nitric oxide generation is required for abscisic acid-induced stomatal closure in Arabidopsis thaliana. Proc. Natl. Acad. Sci. USA 99:16314-16318.

Desikan, R., Hancock, J.T., Bright, J., Harrison, J., Weir, I., Hooley, R., and Neill, S.J. (2005). A role for ETR1 in hydrogen peroxide signaling in stomatal guard cells. Plant Physiol. 137:831-834.

Desikan, R., Last, K., Harrett-Williams, R., Tagliavia, C., Harter, K., Hooley, R., Hancock, J.T., and Neill, S.J. (2006). Ethylene-induced stomatal closure in Arabidopsis occurs via AtrbohF-mediated hydrogen peroxide synthesis. Plant J. 47:907-916.

Desikan, R., Horák, J., Chaban, C., Mira-Rodado, V., Witthöft, J., Elgass, K., Grefen, C., Cheung, M.K., Meixner, A.J., Hooley, R., et al. (2008). The histidine kinase AHK5 integrates endogenous and environmental signals in Arabidopsis guard cells. PLoS One 3:e2491.

de Torres-Zabala, M., Truman, W., Bennett, M.H., Lafforgue, G., Mansfield, J.W., Rodriguez Egea, P., Bögre, L., and Grant, M. (2007). Pseudomonas syringae pv. tomato hijacks the Arabidopsis abscisic acid signalling pathway to cause disease. EMBO J. 26:1434-1443.

Dou, D., and Zhou, J.M. (2012). Phytopathogen effectors subverting host immunity: different foes, similar battleground. Cell Host Microbe 12:484-495

Du, M., Zhai, Q., Deng, L., Li, S., Li, H., Yan, L., Huang, Z., Wang, B., Jiang, H., Huang, T., et al. (2014). Closely related NAC transcription factors of tomato differentially regulate stomatal closure and reopening during pathogen attack. Plant Cell 26:3167-3184.

Elmore, J.M., and Coaker, G. (2011). The role of the plasma membrane $\mathrm{H}^{+}$-ATPase in plant-microbe interactions. Mol. Plant 4:416-427.

Fan, L.M., Zhang, W., Chen, J.G., Taylor, J.P., Jones, A.M., and Assmann, S.M. (2008). Abscisic acid regulation of guard-cell $\mathrm{K}^{+}$and anion channels in Gbeta- and RGS-deficient Arabidopsis lines. Proc. Natl. Acad. Sci. USA 105:8476-8481.

Felix, G., Duran, J.D., Volko, S., and Boller, T. (1999). Plants have a sensitive perception system for the most conserved domain of bacterial flagellin. Plant J. 18:265-276.

Felle, H.H., Herrmann, A., Hanstein, S., Hückelhoven, R., and Kogel, K.H. (2004). Apoplastic pH signaling in barley leaves attacked by the powdery mildew fungus Blumeria graminis f. sp. hordei. Mol. Plant Microbe Interact. 17:118-123.

Freeman, B.C., and Beattie, G.A. (2009). Bacterial growth restriction during host resistance to Pseudomonas syringae is associated with leaf water loss and localized cessation of vascular activity in Arabidopsis thaliana. Mol. Plant Microbe Interact. 22:857-867.

García-Mata, C., and Lamattina, L. (2013). Gasotransmitters are emerging as new guard cell signaling molecules and regulators of leaf gas exchange. Plant Sci. 201-202:66-73.

García-Mata, C., Gay, R., Sokolovski, S., Hills, A., Lamattina, L., and Blatt, M.R. (2003). Nitric oxide regulates $\mathrm{K}^{+}$and $\mathrm{Cl}^{-}$channels in guard cells through a subset of abscisic acid-evoked signaling pathways. Proc. Natl. Acad. Sci. USA 100:11116-11121.

Geiger, D., Scherzer, S., Mumm, P., Stange, A., Marten, I., Bauer, H., Ache, P., Matschi, S., Liese, A., Al-Rasheid, K.A.S., et al. (2009). Activity of guard cell anion channel SLAC1 is controlled by droughtstress signaling kinase-phosphatase pair. Proc. Natl. Acad. Sci. USA 106:21425-21430.

Goel, A.K., Lundberg, D., Torres, M.A., Matthews, R., AkimotoTomiyama, C., Farmer, L., Dangl, J.L., and Grant, S.R. (2008). The 
Pseudomonas syringae type III effector HopAM1 enhances virulence on water-stressed plants. Mol. Plant Microbe Interact. 21:361-370.

Gottig, N., Garavaglia, B.S., Daurelio, L.D., Valentine, A., Gehring, C., Orellano, E.G., and Ottado, J. (2008). Xanthomonas axonopodis pv. citri uses a plant natriuretic peptide-like protein to modify host homeostasis. Proc. Natl. Acad. Sci. USA 105:18631-18636.

Grimmer, M.K., John Foulkes, M., and Paveley, N.D. (2012). Foliar pathogenesis and plant water relations: a review. J. Exp. Bot. 63:4321-4331.

Gudesblat, G.E., lusem, N.D., and Morris, P.C. (2007). Guard cellspecific inhibition of Arabidopsis MPK3 expression causes abnormal stomatal responses to abscisic acid and hydrogen peroxide. New Phytol. 173:713-721.

Gudesblat, G.E., Torres, P.S., and Vojnov, A.A. (2009). Xanthomonas campestris overcomes Arabidopsis stomatal innate immunity through a DSF cell-to-cell signal-regulated virulence factor. Plant Physiol. 149:1017-1027.

Guo, F.Q., Okamoto, M., and Crawford, N.M. (2003). Identification of a plant nitric oxide synthase gene involved in hormonal signaling. Science 302:100-103.

Hao, F., Zhao, S., Dong, H., Zhang, H., Sun, L., and Miao, C. (2010). Nia1 and $\mathrm{Nia} 2$ are involved in exogenous salicylic acid-induced nitric oxide generation and stomatal closure in Arabidopsis. J. Integr. Plant Biol. 52:298-307.

Hok, S., Allasia, V., Andrio, E., Naessens, E., Ribes, E., Panabieres, F., Attard, A., Ris, N., Clement, M., Barlet, X., et al. (2014). The receptor kinase IMPAIRED OOMYCETE SUSCEPTIBILITY 1 attenuates abscisic acid responses in Arabidopsis thaliana. Plant physiol. 166:1506-1518.

Hua, D., Wang, C., He, J., Liao, H., Duan, Y., Zhu, Z., Guo, Y., Chen, Z., and Gong, Z. (2012). A plasma membrane receptor kinase, GHR1, mediates abscisic acid- and hydrogen peroxide-regulated stomatal movement in Arabidopsis. Plant Cell 24:2546-2561.

Huang, P.Y., Yeh, Y.H., Liu, A.C., Cheng, C.P., and Zimmerli, L. (2014). The Arabidopsis LecRK-VI.2 associates with the pattern-recognition receptor FLS2 and primes Nicotiana benthamiana pattern-triggered immunity. Plant J. 79:243-255.

Hugouvieux, V., Barber, C.E., and Daniels, M.J. (1998). Entry of Xanthomonas campestris pv. campestris into hydathodes of Arabidopsis thaliana leaves: a system for studying early infection events in bacterial pathogenesis. Mol. Plant Microbe Interact. 11:537-543.

Issak, M., Okuma, E., Munemasa, S., Nakamura, Y., Mori, I.C., and Murata, Y. (2013). Neither endogenous abscisic acid nor endogenous jasmonate is involved in salicylic acid-, yeast elicitor-, or chitosan-induced stomatal closure in Arabidopsis thaliana. Biosci. Biotechnol. Biochem. 77:1111-1113.

Jammes, F., Song, C., Shin, D., Munemasa, S., Takeda, K., Gu, D., Cho, D., Lee, S., Giordo, R., Sritubtim, S., et al. (2009). MAP kinases MPK9 and MPK12 are preferentially expressed in guard cells and positively regulate ROS-mediated ABA signaling. Proc. Natl. Acad. Sci. USA 106:20520-20525.

Jammes, F., Yang, X., Xiao, S., and Kwak, J.M. (2011). Two Arabidopsis guard cell-preferential MAPK genes, MPK9 and MPK12, function in biotic stress response. Plant Signal. Behav. 6:1875-1877.

Jeandroz, S., Lamotte, O., Astier, J., Rasul, S., Trapet, P., BessonBard, A., Bourque, S., Nicolas-Francès, V., Ma, W., Berkowitz, G.A., et al. (2013). There's more to the picture than meets the eye: nitric oxide cross talk with $\mathrm{Ca}^{2+}$ signaling. Plant Physiol. 163:459-470.

Jeworutzki, E., Roelfsema, M.R.G., Anschütz, U., Krol, E., Elzenga, J.T.M., Felix, G., Boller, T., Hedrich, R., and Becker, D. (2010). Early signaling through the Arabidopsis pattern recognition receptors FLS2 and EFR involves $\mathrm{Ca}^{2+}$-associated opening of plasma membrane anion channels. Plant J. 62:367-378.
Jones, J.D.G., and Dangl, J.L. (2006). The plant immune system. Nature 444:323-329.

Joshi-Saha, A., Valon, C., and Leung, J. (2011). A brand new START: abscisic acid perception and transduction in the guard cell. Sci. Signal. 4:re4.

Kadota, Y., Sklenar, J., Derbyshire, P., Stransfeld, L., Asai, S., Ntoukakis, V., Jones, J.D., Shirasu, K., Menke, F., Jones, A., et al. (2014). Direct regulation of the NADPH oxidase RBOHD by the PRRassociated kinase BIK1 during plant immunity. Mol. Cell 54:43-55.

Katsir, L., Schilmiller, A.L., Staswick, P.E., He, S.Y., and Howe, G.A. (2008). COl1 is a critical component of a receptor for jasmonate and the bacterial virulence factor coronatine. Proc. Natl. Acad. Sci. USA 105:7100-7105.

Keinath, N.F., Kierszniowska, S., Lorek, J., Bourdais, G., Kessler, S.A., Shimosato-Asano, H., Grossniklaus, U., Schulze, W.X., Robatzek, S., and Panstruga, R. (2010). PAMP (pathogen-associated molecular pattern)-induced changes in plasma membrane compartmentalization reveal novel components of plant immunity. J. Biol. Chem. 285:3914039149.

Khokon, M.A.R., Hossain, M.A., Munemasa, S., Uraji, M., Nakamura, Y., Mori, I.C., and Murata, Y. (2010a). Yeast elicitor-induced stomatal closure and peroxidase-mediated ROS production in Arabidopsis. Plant Cell Physiol. 51:1915-1921.

Khokon, M.A.R., Uraji, M., Munemasa, S., Okuma, E., Nakamura, Y., Mori, I.C., and Murata, Y. (2010b). Chitosan-induced stomatal closure accompanied by peroxidase-mediated reactive oxygen species production in Arabidopsis. Biosci. Biotechnol. Biochem. 74:2313-2315.

Khokon, M.A.R., Okuma, E., Hossain, M.A., Munemasa, S., Uraji, M., Nakamura, Y., Mori, I.C., and Murata, Y. (2011). Involvement of extracellular oxidative burst in salicylic acid-induced stomatal closure in Arabidopsis. Plant Cell Environ. 34:434-443.

Kim, T.H., Böhmer, M., Hu, H., Nishimura, N., and Schroeder, J.I. (2010). Guard cell signal transduction network: advances in understanding abscisic acid, $\mathrm{CO}_{2}$, and $\mathrm{Ca}^{2+}$ signaling. Annu. Rev. Plant Biol. 61:561-591.

Klusener, B., Young, J.J., Murata, Y., Allen, G.J., Mori, I.C., Hugouvieux, V., and Schroeder, J.I. (2002). Convergence of calcium signaling pathways of pathogenic elicitors and abscisic acid in Arabidopsis guard cells. Plant Physiol. 130:2152-2163.

Koers, S., Guzel-Deger, A., Marten, I., and Roelfsema, M.R.G. (2011). Barley mildew and its elicitor chitosan promote closed stomata by stimulating guard-cell S-type anion channels. Plant J. 68:670-680.

Korneli, C., Danisman, S., and Staiger, D. (2014). Differential control of pre-invasive and post-invasive antibacterial defense by the Arabidopsis circadian clock. Plant Cell Physiol. 55:1613-1622.

Krol, E., Mentzel, T., Chinchilla, D., Boller, T., Felix, G., Kemmerling, B., Postel, S., Arents, M., Jeworutzki, E., Al-Rasheid, K.A.S., et al. (2010). Perception of the Arabidopsis danger signal peptide 1 involves the pattern recognition receptor AtPEPR1 and its close homologue AtPEPR2. J. Biol. Chem. 285:13471-13479.

Kroupitski, Y., Golberg, D., Belausov, E., Pinto, R., Swartzberg, D., Granot, D., and Sela, S. (2009). Internalization of Salmonella enterica in leaves is induced by light and involves chemotaxis and penetration through open stomata. Appl. Environ. Microbiol. 75:6076-6086.

Kunze, G., Zipfel, C., Robatzek, S., Niehaus, K., Boller, T., and Felix, G. (2004). The $\mathrm{N}$ terminus of bacterial elongation factor Tu elicits innate immunity in Arabidopsis plants. Plant Cell 16:3496-3507.

Kwak, J.M., Mori, I.C., Pei, Z.M., Leonhardt, N., Torres, M.A., Dangl, J.L., Bloom, R.E., Bodde, S., Jones, J.D.G., and Schroeder, J.I. (2003). NADPH oxidase AtrbohD and AtrbohF genes function in ROSdependent ABA signaling in Arabidopsis. EMBO J. 22:2623-2633.

Molecular Plant 8, 566-581, April 2015 @ The Author 2015. 
Lee, S., Choi, H., Suh, S., Doo, I.S., Oh, K.Y., Jeong Choi, E., Schroeder Taylor, A.T., Low, P.S., and Lee, Y. (1999). Oligogalacturonic acid and chitosan reduce stomatal aperture by inducing the evolution of reactive oxygen species from guard cells of tomato and Commelina communis. Plant Physiol. 121:147-152.

Lee, S.C., Lan, W., Buchanan, B.B., and Luan, S. (2009). A protein kinase-phosphatase pair interacts with an ion channel to regulate ABA signaling in plant guard cells. Proc. Natl. Acad. Sci. USA 106:21419-21424.

Lee, S., Rojas, C.M., Ishiga, Y., Pandey, S., and Mysore, K.S. (2013). Arabidopsis heterotrimeric G-proteins play a critical role in host and nonhost resistance against Pseudomonas syringae pathogens. PLoS One 8:e82445.

Li, L., Li, M., Yu, L., Zhou, Z., Liang, X., Liu, Z., Cai, G., Gao, L., Zhang, X., Wang, Y., et al. (2014). The FLS2-associated kinase BIK1 directly phosphorylates the NADPH oxidase RbohD to control plant immunity. Cell Host Microbe 15:329-338.

Lim, C.W., Luan, S., and Lee, S.C. (2014). A prominent role for RCAR3mediated ABA signaling in response to Pseudomonas syringae pv. tomato DC3000 infection in Arabidopsis. Plant Cell Physiol. 55:16911703.

Liu, J., Elmore, J.M., Fuglsang, A.T., Palmgren, M.G., Staskawicz, B.J., and Coaker, G. (2009). RIN4 functions with plasma membrane $\mathrm{H}^{+}$-ATPases to regulate stomatal apertures during pathogen attack. PLoS Biol. 7:e1000139.

Liu, Z., Wu, Y., Yang, F., Zhang, Y., Chen, S., Xie, Q., Tian, X., and Zhou, J.M. (2013). BIK1 interacts with PEPRs to mediate ethylene-induced immunity. Proc. Natl. Acad. Sci. USA 110:6205-6210.

Ma, W., Smigel, A., Tsai, Y.C., Braam, J., and Berkowitz, G.A. (2008). Innate immunity signaling: cytosolic $\mathrm{Ca}^{2+}$ elevation is linked to downstream nitric oxide generation through the action of calmodulin or a calmodulin-like protein. Plant Physiol. 148:818-828.

Ma, W., Qi, Z., Smigel, A., Walker, R.K., Verma, R., and Berkowitz, G.A. (2009). $\mathrm{Ca}^{2+}, \mathrm{CAMP}$, and transduction of non-self perception during plant immune responses. Proc. Natl. Acad. Sci. USA 106:20995-21000.

Ma, Y., Zhao, Y., Walker, R.K., and Berkowitz, G.A. (2013). Molecular steps in the immune signaling pathway evoked by plant elicitor peptides: $\mathrm{Ca}^{2+}$-dependent protein kinases, nitric oxide, and reactive oxygen species are downstream from the early $\mathrm{Ca}^{2+}$ signal. Plant Physiol. 163:1459-1471.

Macho, A.P., Boutrot, F., Rathjen, J.P., and Zipfel, C. (2012). ASPARTATE OXIDASE plays an important role in Arabidopsis stomatal immunity. Plant Physiol. 159:1845-1856.

McLachlan, D.H., Kopischke, M., and Robatzek, S. (2014). Gate control: guard cell regulation by microbial stress. New Phytol. 203:1049-1063.

Melotto, M., Underwood, W., Koczan, J., Nomura, K., and He, S.Y. (2006). Plant stomata function in innate immunity against bacterial invasion. Cell 126:969-980.

Melotto, M., Underwood, W., and He, S.Y. (2008). Role of stomata in plant innate immunity and foliar bacterial diseases. Annu. Rev. Phytopathol. 46:101-122.

Melotto, M., Panchal, S., and Roy, D. (2014). Plant innate immunity against human bacterial pathogens. Front. Microbiol. 5:411.

Merilo, E., Laanemets, K., Hu, H., Xue, S., Jakobson, L., Tulva, I., Gonzalez-Guzman, M., Rodriguez, P.L., Schroeder, J.I., Broschè, M., et al. (2013). PYR/RCAR receptors contribute to ozone-, reduced air humidity-, darkness-, and $\mathrm{CO}_{2}$-induced stomatal regulation. Plant Physiol. 162:1652-1668.

Merlot, S., Leonhardt, N., Fenzi, F., Valon, C., Costa, M., Piette, L., Vavasseur, A., Genty, B., Boivin, K., Müller, A., et al. (2007). Constitutive activation of a plasma membrane $\mathrm{H}^{+}$-ATPase prevents abscisic acid-mediated stomatal closure. EMBO J. 26:3216-3226.
Mersmann, S., Bourdais, G., Rietz, S., and Robatzek, S. (2010). Ethylene signaling regulates accumulation of the FLS2 receptor and is required for the oxidative burst contributing to plant immunity. Plant Physiol. 154:391-400.

Mittal, S., and Davis, K.R. (1995). Role of the phytotoxin coronatine in the infection of Arabidopsis thaliana by Pseudomonas syringae pv. tomato. Mol. Plant Microbe Interact. 8:165-171.

Monaghan, J., and Zipfel, C. (2012). Plant pattern recognition receptor complexes at the plasma membrane. Curr. Opin. Plant Biol. 15:349-357.

Montillet, J.L., Leonhardt, N., Mondy, S., Tranchimand, S., Rumeau, D., Boudsocq, M., Garcia, A.V., Douki, T., Bigeard, J., Laurière, C., et al. (2013). An abscisic acid-independent oxylipin pathway controls stomatal closure and immune defense in Arabidopsis. PLoS Biol. 11:e1001513.

Moreau, M., Lee, G.I., Wang, Y., Crane, B.R., and Klessig, D.F. (2008). AtNOS/AtNOA1 is a functional Arabidopsis thaliana cGTPase and not a nitric-oxide synthase. J. Biol. Chem. 283:32957-32967.

Mori, I.C., Pinontoan, R., Kawano, T., and Muto, S. (2001). Involvement of superoxide generation in salicylic acid-induced stomatal closure in Vicia faba. Plant Cell Physiol. 42:1383-1388.

Mori, I.C., Murata, Y., Yang, Y., Munemasa, S., Wang, Y.F., Andreoli, S., Tiriac, H., Alonso, J.M., Harper, J.F., Ecker, J.R., et al. (2006). CDPKs CPK6 and CPK3 function in ABA regulation of guard cell Stype anion- and $\mathrm{Ca}^{2+}$ - permeable channels and stomatal closure. PLoS Biol. 4:e327.

Munemasa, S., Oda, K., Watanabe-Sugimoto, M., Nakamura, Y., Shimoishi, Y., and Murata, Y. (2007). The coronatine-insensitive 1 mutation reveals the hormonal signaling interaction between abscisic acid and methyl jasmonate in Arabidopsis guard cells. Specific impairment of ion channel activation and second messenger production. Plant Physiol. 143:1398-1407.

Murata, Y., Pei, Z.M., Mori, I.C., and Schroeder, J. (2001). Abscisic acid activation of plasma membrane $\mathrm{Ca}^{2+}$ channels in guard cells requires cytosolic $\mathrm{NAD}(\mathrm{P}) \mathrm{H}$ and is differentially disrupted upstream and downstream of reactive oxygen species production in abi1-1 and abi2-1 protein phosphatase 2C mutants. Plant Cell 13:2513-2523.

Mustilli, A.C., Merlot, S., Vavasseur, A., Fenzi, F., and Giraudat, J. (2002). Arabidopsis OST1 protein kinase mediates the regulation of stomatal aperture by abscisic acid and acts upstream of reactive oxygen species production. Plant Cell 14:3089-3099.

Nühse, T.S., Bottrill, A.R., Jones, A.M.E., and Peck, S.C. (2007). Quantitative phosphoproteomic analysis of plasma membrane proteins reveals regulatory mechanisms of plant innate immune responses. Plant J. 51:931-940.

O'Brien, J.A., Daudi, A., Butt, V.S., and Bolwell, P.G. (2012). Reactive oxygen species and their role in plant defence and cell wall metabolism. Planta 236:765-779.

Okada, M., Ito, S., Matsubara, A., Iwakura, I., Egoshi, S., and Ueda, M. (2009). Total syntheses of coronatines by exo-selective Diels-Alder reaction and their biological activities on stomatal opening. Org. Biomol. Chem. 7:3065-3073.

Pantin, F., Renaud, J., Barbier, F., Vavasseur, A., Le Thiec, D., Rose, C., Bariac, T., Casson, S., McLachlan, D.H., Hetherington, A.M., et al. (2013). Developmental priming of stomatal sensitivity to abscisic acid by leaf microclimate. Curr. Biol. 23:1805-1811.

Pei, Z.M., Murata, Y., Benning, G., Thomine, S., Klusener, B., Allen, G.J., Grill, E., and Schroeder, J.I. (2000). Calcium channels activated by hydrogen peroxide mediate abscisic acid signalling in guard cells. Nature 406:731-734.

Pham, J., Liu, J., Bennett, M.H., Mansfield, J.W., and Desikan, R. (2012). Arabidopsis histidine kinase 5 regulates salt sensitivity and 
resistance against bacterial and fungal infection. New Phytol. 194:168180.

Robert-Seilaniantz, A., Grant, M., and Jones, J.D.G. (2011). Hormone crosstalk in plant disease and defense: more than just jasmonatesalicylate antagonism. Annu. Rev. Phytopathol. 49:317-343.

Roy, D., Panchal, S., Rosa, B.A., and Melotto, M. (2013). Escherichia coli 0157:H7 induces stronger plant immunity than Salmonella enterica Typhimurium SL1344. Phytopathology 103:326-332.

Salam, M.A., Jammes, F., Hossain, M.A., Ye, W., Nakamura, Y., Mori, I.C., Kwak, J.M., and Murata, Y. (2012). MAP kinases, MPK9 and MPK12, regulate chitosan-induced stomatal closure. Biosci. Biotechnol. Biochem. 76:1785-1787.

Salam, M.A., Jammes, F., Hossain, M.A., Ye, W., Nakamura, Y., Mori, I.C., Kwak, J.M., and Murata, Y. (2013). Two guard cell-preferential MAPKs, MPK9 and MPK12, regulate YEL signalling in Arabidopsis guard cells. Plant Biol. (Stuttg) 15:436-442.

Schellenberg, B., Ramel, C., and Dudler, R. (2010). Pseudomonas syringae virulence factor syringolin A counteracts stomatal immunity by proteasome inhibition. Mol. Plant Microbe Interact. 23:1287-1293.

Schikora, A., Garcia, A.V., and Hirt, H. (2012). Plants as alternative hosts for Salmonella. Trends Plant Sci. 17:245-249.

Singh, P., Kuo, Y.C., Mishra, S., Tsai, C.H., Chien, C.C., Chen, C.W., Desclos-Theveniau, M., Chu, P.W., Schulze, B., Chinchilla, D., et al. (2012). The lectin receptor kinase-VI.2 is required for priming and positively regulates Arabidopsis pattern-triggered immunity. Plant Cell 24:1256-1270.

Sirichandra, C., Gu, D., Hu, H.C., Davanture, M., Lee, S., Djaoui, M., Valot, B., Zivy, M., Leung, J., Merlot, S., et al. (2009a). Phosphorylation of the Arabidopsis AtrbohF NADPH oxidase by OST1 protein kinase. FEBS Lett. 583:2982-2986.

Sirichandra, C., Wasilewska, A., Vlad, F., Valon, C., and Leung, J. (2009b). The guard cell as a single-cell model towards understanding drought tolerance and abscisic acid action. J. Exp. Bot. 60:1439-1463.

Srivastava, N., Gonugunta, V., Puli, M., and Raghavendra, A. (2009). Nitric oxide production occurs downstream of reactive oxygen species in guard cells during stomatal closure induced by chitosan in abaxial epidermis of Pisum sativum. Planta 229:757-765.

Suhita, D., Raghavendra, A.S., Kwak, J.M., and Vavasseur, A. (2004). Cytoplasmic alkalization precedes reactive oxygen species production during methyl jasmonate- and abscisic acid-induced stomatal closure. Plant Physiol. 134:1536-1545.

Sun, L.R., Hao, F.S., Lu, B.S., and Ma, L.Y. (2010). AtNOA1 modulates nitric oxide accumulation and stomatal closure induced by salicylic acid in Arabidopsis. Plant Signal. Behav. 5:1022-1024.

Tanaka, Y., Sano, T., Tamaoki, M., Nakajima, N., Kondo, N., and Hasezawa, S. (2005). Ethylene inhibits abscisic acid-induced stomatal closure in Arabidopsis. Plant Physiol. 138:2337-2343.

Ton, J., Flors, V., and Mauch-Mani, B. (2009). The multifaceted role of ABA in disease resistance. Trends Plant Sci. 14:310-317.

Torres, M.A. (2010). ROS in biotic interactions. Physiol. Plant. 138:414-429.

Torres, M.A., Dangl, J.L., and Jones, J.D.G. (2002). Arabidopsis gp91phox homologues AtrbohD and AtrbohF are required for accumulation of reactive oxygen intermediates in the plant defense response. Proc. Natl. Acad. Sci. USA 99:517-522.

Valério, L., De Meyer, M., Penel, C., and Dunand, C. (2004). Expression analysis of the Arabidopsis peroxidase multigenic family. Phytochemistry 65:1331-1342.

Wang, P., and Song, C.P. (2008). Guard-cell signalling for hydrogen peroxide and abscisic acid. New Phytol. 178:703-718.
Wang, X.Q., Ullah, H., Jones, A.M., and Assmann, S.M. (2001). G protein regulation of ion channels and abscisic acid signaling in Arabidopsis guard cells. Science 292:2070-2072.

Wright, C.A., and Beattie, G.A. (2004). Pseudomonas syringae pv. tomato cells encounter inhibitory levels of water stress during the hypersensitive response of Arabidopsis thaliana. Proc. Natl. Acad. Sci. USA 101:3269-3274.

Xin, X.F., and He, S.Y. (2013). Pseudomonas syringae pv. tomato DC3000: a model pathogen for probing disease susceptibility and hormone signaling in plants. Annu. Rev. Phytopathol. 51:473-498.

Ye, W., Muroyama, D., Munemasa, S., Nakamura, Y., Mori, I.C., and Murata, Y. (2013). Calcium-dependent protein kinase CPK6 positively functions in induction by yeast elicitor of stomatal closure and inhibition by yeast elicitor of light-induced stomatal opening in Arabidopsis. Plant Physiol. 163:591-599.

Yun, B.W., Feechan, A., Yin, M., Saidi, N.B.B., Le Bihan, T., Yu, M., Moore, J.W., Kang, J.G., Kwon, E., Spoel, S.H., et al. (2011). Snitrosylation of NADPH oxidase regulates cell death in plant immunity. Nature 478:264-268.

Zeidler, D., Zahringer, U., Gerber, I., Dubery, I., Hartung, T., Bors, W., Hutzler, P., and Durner, J. (2004). Innate immunity in Arabidopsis thaliana: lipopolysaccharides activate nitric oxide synthase (NOS) and induce defense genes. Proc. Natl. Acad. Sci. USA 101:15811-15816.

Zeng, W., and He, S.Y. (2010). A prominent role of the flagellin receptor FLAGELLIN-SENSING2 in mediating stomatal response to Pseudomonas syringae pv tomato DC3000 in Arabidopsis. Plant Physiol. 153:1188-1198.

Zeng, W., Brutus, A., Kremer, J.M., Withers, J.C., Gao, X., Jones, A.D., and He, S.Y. (2011). A genetic screen reveals Arabidopsis stomatal and/or apoplastic defenses against Pseudomonas syringae pv. tomato DC3000. PLoS Pathog. 7:e1002291.

Zhang, J., Shao, F., Li, Y., Cui, H., Chen, L., Li, H., Zou, Y., Long, C., Lan, L., Chai, J., et al. (2007). A Pseudomonas syringae effector inactivates MAPKs to suppress PAMP-induced immunity in plants. Cell Host Microbe 1:175-185.

Zhang, W., He, S.Y., and Assmann, S.M. (2008). The plant innate immunity response in stomatal guard cells invokes G-proteindependent ion channel regulation. Plant J. 56:984-996.

Zhang, J., Li, W., Xiang, T., Liu, Z., Laluk, K., Ding, X., Zou, Y., Gao, M., Zhang, X., Chen, S., et al. (2010). Receptor-like cytoplasmic kinases integrate signaling from multiple plant immune receptors and are targeted by a Pseudomonas syringae effector. Cell Host Microbe 7:290-301.

Zhang, W., Jeon, B.W., and Assmann, S.M. (2011). Heterotrimeric G-protein regulation of ROS signalling and calcium currents in Arabidopsis guard cells. J. Exp. Bot. 62:2371-2379.

Zhang, C., Xie, Q., Anderson, R.G., Ng, G., Seitz, N.C., Peterson, T., McClung, C.R., McDowell, J.M., Kong, D., Kwak, J.M., et al. (2013). Crosstalk between the circadian clock and innate immunity in Arabidopsis. PLoS Pathog. 9:e1003370.

Zheng, X.Y., Spivey, N.W., Zeng, W., Liu, P.P., Fu, Z.Q., Klessig, D.F., He, S.Y., and Dong, X. (2012). Coronatine promotes Pseudomonas syringae virulence in plants by activating a signaling cascade that inhibits salicylic acid accumulation. Cell Host Microbe 11:587-596.

Zipfel, C., Robatzek, S., Navarro, L., Oakeley, E.J., Jones, J.D.G., Felix, G., and Boller, T. (2004). Bacterial disease resistance in Arabidopsis through flagellin perception. Nature 428:764-767.

Zipfel, C., Kunze, G., Chinchilla, D., Caniard, A., Jones, J.D.G., Boller, T., and Felix, G. (2006). Perception of the bacterial PAMP EF-Tu by the receptor EFR restricts Agrobacterium-mediated transformation. Cell 125:749-760. 